\title{
EL AVANCE DE LA GENTRIFICACIÓN EN BARCELONA Y MADRID, 2011-2019: ANÁLISIS SOCIOESPACIAL A PARTIR DE UN ÍNDICE DE GENTRIFICACIÓN
}

\author{
Antonio López-Gay \\ Departament de Geografia, Universitat Autònoma de Barcelona y Centre d’Estudis Demogràfics (CED-CERCA) \\ tlopez@ced.uab.cat \\ ORCID iD: https://orcid.org/0000-0001-8892-2816 \\ Joan Sales-Favà \\ Departament de Salut, Generalitat de Catalunya \\ joan.sales@gencat.cat \\ ORCID iD: https://orcid.org/0000-0002-2346-9552 \\ Miguel Solana-Solana \\ Departament de Geografia, Universitat Autònoma de Barcelona \\ AntonioMiguel.Solana@uab.cat \\ ORCID iD: https://orcid.org/0000-0002-0811-1990

\section{Ana Fernández} \\ Servei de Salut Comunitària. Agència de Salut Pública de Barcelona \\ afernand@aspb.cat \\ ORCID iD: https://orcid.org/0000-0002-0333-1345

\section{Andrés Peralta} \\ Instituto de Salud Pública, Pontificia Universidad Católica del Ecuador \\ aperalta@aspb.cat \\ ORCID iD: https://orcid.org/0000-0002-7617-108X
}

Recibido: 04/05/2021; Aceptado: 12/11/2021; Publicado: 29/12/2021

Cómo citar este artículo/citation: López-Gay, Antonio; Sales-Favà, Joan; Solana-Solana, Miguel; Fernández, Ana; Peralta, Andrés (2021). El avance de la gentrificación en Barcelona y Madrid, 2011-2019: análisis socioespacial a partir de un índice de gentrificación. Estudios Geográficos, 82 (291), e084. https://doi.org/10.3989/estgeogr.202195.095

RESUMEN: Las causas y los efectos de la gentrificación han recibido en los últimos años una amplia cobertura por parte de investigadores, administraciones públicas, entidades sociales y medios de comunicación, entre otros. Pese a todo, aún disponemos de poca evidencia cuantitativa que permita diseccionar la diversidad de elementos sociodemográficos que han intervenido en los procesos de gentrificación de las ciudades españolas. En el presente artículo queremos contribuir a ampliar este tipo de aproximación a través de dos ejes principales de análisis. En primer lugar, calculamos un índice de gentrificación que mide la intensidad de los procesos de transformación sociodemográfica en los barrios de Barcelona y Madrid desde 2011 hasta 2019 con base en datos homogéneos de stock (lecturas del padrón municipal) y de flujos (registros de cambios de domicilio y migraciones). En segundo lugar, comparamos los patrones espaciales del índice y exploramos las similitudes y singularidades con las que se ha manifestado la gentrificación a partir de los siguientes ejes de análisis, asociados a la vulnerabilidad social de los barrios: (i) perfil de los nuevos habitantes, (ii) expulsión y desplazamiento de la población y (iii) velocidad del cambio poblacional. Los resultados muestran la expansión de la gentrificación hacia áreas que habían permanecido ajenas a estas dinámicas, así como la existencia de rasgos distintivos en los procesos de ambas ciudades.

PALABRAS CLAVE: índice de gentrificación, cambio urbano, estratificación social, vulnerabilidad social, movilidad residencial, desplazamiento, barrio

\section{The spread of gentrification in Barcelona and Madrid, 2011-2019: socio-spatial analysis using an index} of gentrification

ABSTRACT: The causes and effects of gentrification have received extensive coverage in recent years by researchers, public administrations, social entities and the media, among others. However, we still have little quantitative evidence available to dissect the diversity of sociodemographic factors that have been involved in the gentrification processes of Spanish cities. In this paper, we aim at contributing to expand 
this type of approach by two main axes of analysis. First, we calculate a gentrification index to measure the intensity of sociodemographic transformation processes in the neighborhoods of Barcelona and Madrid from 2011 to 2019 based on consistent stock data (population register) and flow data (records of residential and migration changes). Second, we compare the spatial patterns of the index and explore the similarities and singularities that gentrification processes have occurred through the following axes of analysis, which are closely associated with social vulnerability of the neighborhoods: (i) profile of new inhabitants, (ii) population displacement, and (iii) speed of population change. Our results reveal the expansion of gentrification into areas that had previously remained unaffected by these dynamics, and the distinctive features of the processes in each city.

Keywords: index of gentrification, urban change, social stratification, social vulnerability, residential mobility, displacement, neighborhood.

Copyright: @ 2021 CSIC. Este es un artículo de acceso abierto distribuido bajo los términos de la licencia de uso y distribución Creative Commons Reconocimiento 4.0 Internacional (CC BY 4.0).

\section{INTRODUCCIÓN}

En los últimos años se han intensificado los procesos de reconfiguración socioespacial de la población en las grandes ciudades occidentales, de forma que los diferentes grupos sociales se estarían alejando territorialmente, contribuyendo así a un aumento de la segregación y de la polarización socioeconómica. En esta reestructuración urbana predominan dos procesos. Por un lado, las ciudades centrales refuerzan su carácter excluyente en un escenario de marcada revalorización vinculada a la concentración de nuevas actividades productivas y de innovación. Por el otro lado, los grupos socioeconómicos más vulnerables serían desplazados y concentrados en espacios periféricos, normalmente privados de un buen acceso a diferentes tipos de servicios (Bailey y Milton, 2018; Hochstenbach y Musterd, 2021).

La gentrificación es el ejemplo más local de este proceso general, y ha reforzado las áreas del centro de la ciudad como espacios exclusivos, dificultando el acceso a la vivienda y contribuyendo al desplazamiento de los antiguos residentes. La del 2010 ha sido, hasta ahora, la década de la gentrificación en España. En este periodo, los procesos de gentrificación se han expandido con intensidad en las grandes ciudades españolas, llegando a barrios que habían permanecido ajenos a este tipo de dinámicas (Sorando y Ardura, 2018). La gentrificación ya forma parte de las agendas urbanas como fenómeno a abordar y ocupa un lugar central en debates como los del acceso a la vivienda, la inseguridad residencial, los usos del suelo o los planes de reforma urbana, entre otros. Además, hemos visto como un concepto acuñado en el ámbito académico ha sido incorporado al vocabulario habitual de los medios de comunicación e incluso de las conversaciones cotidianas.

El punto de convergencia de las diferentes disciplinas que han definido la gentrificación es el proceso de transformación sociodemográfica de un determinado territorio. Este proceso estaría generado por la llegada de residentes de condiciones socioeconómicas medias y altas que contribuyen a la expulsión de los antiguos residentes, que generalmente pertenecen a grupos con menos recursos económicos. En el contexto de producción capitalista del espacio urbano se experimentan otros cambios, como la transformación del mercado de la vivienda, del tejido comercial o del espacio público (Benach y Albet, 2018).

Pese a que la gentrificación fue definida hace más de cinco décadas (Glass, 1964), el abordaje cuantitativo del proceso de sustitución y desplazamiento de la población ha tenido menor recorrido que su tratamiento teórico. Académicos e instituciones públicas de ámbito local y regional han tratado de medir, desde lo cuantitativo, la gentrificación (Freeman, 2005; Atkinson, Wulff, Reynolds y Spinney, 2011; Ding, Hwang y Divringi, 2016). En general, estas aproximaciones han buscado categorizar los barrios según la intensidad del proceso o el riesgo de ser gentrificados utilizando variables poblacionales, geográficas y/o urbanísticas. Pese a todo, la diversidad de las fuentes de cada país y la dificultad de profundizar en los procesos de sustitución, y especialmente de desplazamiento (Hamnett, 2000; Newman y Wyly, 2006), a través de los datos, explican la falta de una metodología común y estándar para medir estos procesos a nivel internacional.

En este artículo proponemos un ejercicio metodológico y conceptual con el fin de calcular un índice compuesto que calibre la intensidad de los procesos de transformación sociodemográfica afines a la gentrificación que han experimentado los barrios de Barcelona y Madrid desde 2011 hasta 2019. El índice incluye seis dimensiones conceptuales asociadas a diferentes vectores de transformación socioeconómica de los barrios y que se explicarán con detalle en el apartado metodológico. Una de las innovaciones de este índice es la diversa naturaleza de las fuentes utilizadas, ya que contempla la utilización de fuentes demográficas de stock (la Estadística del Padrón Con- 
tinuo), de flujos (los registros de altas y bajas del Padrón Municipal por cambio de domicilio y migración) y las características asociadas a los hogares. El resultado final del ejercicio no solo nos permite identificar la intensidad con la que los barrios de Barcelona y Madrid han vivido procesos de gentrificación en los últimos años, sino también, y quizás más interesante, analizar cómo se propagan las diferentes dimensiones de transformación, destapando así vulnerabilidades en el territorio urbano. El índice compuesto final se ha calculado en función de unos parámetros comunes que permiten comparar los valores de los barrios de una y otra ciudad.

\section{LA APROXIMACIÓN CUANTITATIVA A LOS PROCESOS DE GENTRIFICACIÓN}

\subsection{La gentrificación en España}

El estudio de la gentrificación en ciudades españolas cuenta ya con un recorrido dilatado, especialmente en lo referente al análisis de casos específicos. Algunos barrios sobre los que se han desarrollado este tipo de aproximaciones son Albaicín en Granada (Duque-Calvache, 2010), Triana o San Bernardo en Sevilla (Díaz Parra, 2009), el Barri Gòtic y el Raval en Barcelona (Cocola-Gant, 2018; Martínez Rigol, 2000) o Lavapiés en Madrid (Sequera, 2013), solo por citar algunos. Durante la década de 2010 tanto los procesos de gentrificación como su estudio, se han expandido de forma considerable. Por un lado, este tipo de dinámicas ha emergido en un mayor número de ciudades y lo ha hecho de forma diversificada (Janoschka, Sequera y Salinas, 2014; Janoschka, 2018). Por el otro, ha ensanchado su espacio de influencia en las grandes urbes españolas, llegando a barrios que hasta ahora habían permanecido ajenos a estos procesos (Sorando y Ardura, 2018; López-Gay, Andújar-Llosa y Salvati, 2020)

Si bien la gentrificación es un fenómeno global (Lees, Bang Shin y López-Morales, 2016), cada territorio, y en este caso España, cuenta con condicionantes específicos fruto del marco legal y de las características socioeconómicas. Entre ellos, podemos destacar el peso de la propiedad como forma residencial mayoritaria entre los hogares (Módenes y-López-Colás, 2014), la poca relevancia del mercado de vivienda pública (Trilla et al., 2018), la indefensión e inseguridad residencial de los inquilinos (Módenes, 2019; Solana-Solana, Ortiz-Guitart y López-Gay, 2020), el impacto de la actividad turística urbana en el tejido social y residencial, tanto en ámbitos insulares (Herrera, Smith y Vera, 2007; Yrigoy, 2017;
Vives-Miró y Rullán, 2017; Domínguez-Mujica, ParreñoCastellano, y Moreno-Medina, 2020) como en peninsulares (Cocola-Gant, 2018; Garcia-López, Jofre-Monseny, Martínez-Mazza, y Segú, 2020), el crecimiento de la población flotante de origen internacional (DomínguezMujica, González-Pérez, Parreño-Castellano, y SánchezAguilera, 2021; López-Gay, Cocola-Gant y Russo, 2021), las particularidades arquitectónicas y las características urbanísticas de los centros urbanos (Rousseau, 2009; Kovács, 2013) o las facilidades que el gobierno español ha generado al mercado financiero internacional para especular con la vivienda (Nel·lo, 2018; Byrne, 2020).

Algunas de estas singularidades y características actúan conjuntamente en las ciudades españolas acelerando o demorando los procesos de gentrificación a micro-escala. Por lo tanto, son elementos que deben tomarse en consideración para poder explicar los recientes cambios residenciales entre los barrios de las grandes ciudades. Además, es necesario contemplar el impacto de las transformaciones del entorno urbano en las variaciones de las preferencias residenciales (Vila Márquez, 2016; Anguelovski, Connolly, Masip, y Pearsall, 2018). Estos cambios no solo articulan las preferencias residenciales de los vecinos sino también de los turistas (o, mejor dicho, del sector turístico), de los intereses inmobiliarios, de las inversiones transnacionales $y$, como hemos mencionado, de una población flotante internacional con un perfil muy cualificado, móvil y transitorio (Cocola-Gant y López-Gay, 2020).

El aumento de la competencia por un bien básico como la vivienda, y especialmente por el segmento de mercado dedicado al alquiler, genera problemas añadidos al conglomerado de población con menos recursos (jóvenes, inmigrantes, familias monoparentales, etc.), justamente aquellos que solo tienen el alquiler como opción residencial. Las desigualdades sociales y territoriales se ven agravadas por los procesos de gentrificación, y especialmente por el desplazamiento de población (Martínez García, 2013; Sarasa, Navarro y Porcel, 2017). Además, España no se ha caracterizado por articular políticas a largo plazo que hayan permitido asegurar el acceso del conjunto de la población a la vivienda (Donat, 2018). La consecuencia general de todos estos factores es un incremento de la segregación residencial en las principales áreas urbanas españolas y, por ende, un aumento de las desigualdades socioeconómicas (Rubiales, 2016; López-Gay, 2018; Porcel, Navarro-Varas, Antón-Alonso y Cruz, 2018; Sorando y Leal, 2019). 
2.2 Un barómetro para medir los cambios sociodemográficos: indicadores para estudiar la gentrificación

La creación de un índice que permita detectar los procesos de gentrificación y su intensidad tiene que contemplar el reto de identificar un proceso global, pero que suele manifestarse con singularidades y características locales. Como señala Sassen (1991) la gentrificación no es un concepto cerrado ni aislado, sino que, como sucede en otros procesos urbanos y residenciales, se transforma y adapta a cada realidad local. Además, la disponibilidad y la calidad de los datos sociodemográficos y urbanísticos condicionan las propiedades del índice. Ahora bien, entre todos los autores siempre existe una cierta voluntad de generar un indicador replicable para otras realidades y que recoja los fundamentos básicos del fenómeno. Por esta razón, es relevante tener en cuenta las experiencias previas. En la Tabla 1 recopilamos las principales variables sociodemográficas y geográficas utilizadas para crear índices de gentrificación. En muchos casos el consenso que generan determinadas variables proviene de la relevancia teórica que se les atribuye para explicar los procesos de gentrificación.

Del estudio de los conceptos e indicadores recogidos en la Tabla 1, así como de los autores y proyectos detrás de estos trabajos, podemos destacar diferentes singularidades que nos serán útiles para después crear nuestro índice compuesto de gentrificación.

En primer lugar, es importante tener en cuenta que algunos de los índices provienen de la colaboración entre instituciones gubernamentales de carácter local o regional, movimientos sociales organizados y grupos de investigación académica. Sería el caso de los análisis llevados a cabo en diferentes regiones urbanas de Estados Unidos bajo el paraguas del Urban Displacement Project. En segundo lugar, la mayoría de índices para analizar la gentrificación se construyen desde un análisis de datos de stocks. Es decir, identifican una variable afectada por el proceso (nivel de estudios, renta, estructura por edad, características de las viviendas, etc.) y comparan el cambio de esta variable entre dos momentos concretos o analizan la presencia de estas características en un momento específico. No obstante, también hay estudios que enfatizan la perspectiva de flujos, y analizan la composición de la población que llega o abandona las unidades analizadas durante un período temporal delimitado. Normalmente, por la tipología de información requerida para realizar cada uno de los análisis pocas veces se realiza el segundo. Finalmente, los índices analizados se pueden dividir entre aquellos que miden el riesgo o la potencialidad de un área a ser gentrificada y los que miden la intensidad del fenómeno en una zona específica.

En España son varias las propuestas que recientemente se han realizado para calcular un índice de gentrificación (Riera, 2018; Sales-Favà, 2019; Díaz Parra y Apaolaza, 2020). En este caso, Barcelona y Madrid son los ámbitos territoriales que se han tenido normalmente en cuenta debido a sus dimensiones, su importancia económica y social, y las tensiones que refleja el mercado de la vivienda fruto de los procesos de incremento de la desigualdad económica y los procesos de gentrificación. Estos trabajos corren en paralelo con una mayor tradición de estudios en que se ha intentado medir los procesos de segregación socioespacial (Rubiales, Bayona y Pujadas, 2012; Porcel,2016; Sorando y Leal, 2019), y que también proponen la creación de indicadores cuantitativos que permitan detectar el proceso y su evolución e intensidad.

Como en el caso de los índices anteriormente mencionados, las variables seleccionadas para medir la gentrificación hacen referencia, principalmente, a dos aspectos: características sociodemográficas de la po-

TABLA 1

ASPECTOS MÁS RELEVANTES UTILIZADOS EN LOS INDICADORES PARA CARACTERIZAR LA GENTRIFICACIÓN

\begin{tabular}{|l|l|}
\hline \multicolumn{1}{|c|}{ Concepto } & \multicolumn{1}{c|}{ Autores } \\
\hline Origen de la población & (Atkinson, 2000; I-team, 2016; Bianco et al., 2018*; Verma, Rinzler, Zuk, DaSilva y Kaplan, 2018*) \\
\hline Condición socioeconómica & (Freeman, 2005; Sorando y Ardura, 2018; Ding et al., 2016; Martin y Beck, 2018) \\
\hline Hogares y cambios de valores & (Hall, Ogden y Hill, 1997; Atkinson, 2000; Ogden y Schnoebelen, 2005; Atkinson et al., 2011) \\
\hline Estructura por edades & (Atkinson, 2000; Atkinson et al., 2011; Moos, Revington, Wilkin y Andrey, 2019; Riera, 2018) \\
\hline Alta movilidad y rotación & (Newman y Wyly, 2006; Atkinson et al., 2011; Rérat y Lees, 2011) \\
\hline Características de la vivienda & (Freeman, 2005; I-team, 2016; Verma et al., 2018*; Riera, 2018) \\
\hline Localización y características de la zona & (Freeman, 2005; I-team, 2016; Bianco et al., 2018*; Verma et al., 2018*) \\
\hline
\end{tabular}

Fuente: Elaboración propia. Nota: *Urban Displacement Project 
blación (sobre todo enfatizan la estructura por edad, el origen/etnia, el nivel de estudios, la relación con la actividad, el tipo de ocupación, los ingresos y rentas individuales y familiares y el tipo de hogar) y vivienda (precio, régimen de tenencia y características de la vivienda, principalmente). Además, y según el objetivo del estudio, se introducen otras variables ad hoc, como en el caso de estudios sobre la gentrificación verde (Anguelovski et al., 2018), que tienen en cuenta la existencia y proximidad a espacios de ocio, parques y jardines en el municipio de Barcelona. En algunos casos, el índice se construye con pocas variables. En el ejemplo de Antón-Alonso, Porcel y Cruz (2018) se proponen dos: la proporción de población trabajadora y desinversión y degradación del parque residencial. Sorando y Ardura (2018), sin la voluntad específica de crear un índice sobre gentrificación en su estudio sobre las dinámicas de gentrificación de diversas ciudades españolas (Barcelona, Bilbao, Madrid, Sevilla, Valencia y Zaragoza), utilizan también indicadores de stock pero desde una perspectiva comparada entre los años 2001-2011. En este caso, la gentrificación se evalúa a partir de los cambios en la composición profesional y de los niveles de estudio de la población residente.

En el próximo apartado detallamos las características del índice que proponemos, que incluye las principales dimensiones que hemos identificado hasta ahora y que combina las dos miradas que hemos subrayado hasta ahora, la de stock y la de flujo.

\section{Metodología. UnA PROPUESTA PARA la CUANTIFI- CACIÓN DE LA GENTRIFICACIÓN EN LAS CIUDADES ESPA- ÑOLAS}

\subsection{Fuentes estadísticas y escala de análisis}

Uno de los principales objetivos de este trabajo es el de generar un índice que nos permita analizar cómo han avanzado las transformaciones sociodemográficas asociadas a los procesos de gentrificación durante la década de 2010 en el espacio interno de los dos municipios españoles más poblados, Madrid y Barcelona. Entre los aspectos más innovadores de nuestra propuesta se encuentra la diversidad de dimensiones sociodemográficas que recogemos, así como el uso pionero de algunos datos específicos. El índice de gentrificación que hemos elaborado se alimenta íntegramente de la explotación de un registro administrativo, el Padrón Municipal de Habitantes, con datos entre el 1 de enero de 2011 y el 1 de enero de 2019. Acudimos a tres fuentes de información que proporcionan datos sobre este registro: (i) la Estadística del Padrón Continuo que realiza el Instituto Nacional de Estadística, (ii) la lectura municipal del Padrón Continuo a nivel de hogar y (iii) los registros de altas y bajas del Padrón Municipal por cambio de domicilio y migración, que han sido proporcionados por ambos ayuntamientos. Esta última fuente de información proporciona una variable socioeconómica, el nivel de estudios, que no está disponible en los ficheros de microdatos de la Estadística del Padrón Continuo. El nivel educativo es un buen índice sobre el capital cultural y social del individuo, un agente relevante en el desarrollo de los procesos de gentrificación (Bridge, 2006) y que está altamente correlacionado con la condición socioeconómica en el caso de las ciudades españolas (Rubiales, 2017). Además, al trabajar con registros de movimientos, nos aseguramos que el nivel educativo está correctamente actualizado, ya que las personas lo declaran en el momento de formalizar el cambio residencial.

Utilizamos el barrio como escala geográfica de análisis y seguimos la división oficial de ambos municipios, basada en criterios históricos y sociodemográficos (Anexo 1). Sin embargo, y por razones de representatividad, hemos agrupado todos los barrios en los que en 2011 residían menos de 3.000 habitantes con las unidades limítrofes más parecidas en términos de renta. Así, hemos pasado de la división original de 200 barrios (73 en Barcelona y 127 en Madrid, a inicio del periodo analizado), a una de 190 barrios (67 en Barcelona y 123 en Madrid). La unidad de análisis, el barrio, es altamente comparable entre los dos municipios, ya que su población media ronda las 25.000 personas en ambos casos. La distribución también es similar: en el $25 \%$ de los barrios más poblados residen más de 32.000 personas en Barcelona y de 35.000 en Madrid, y en el $25 \%$ de los menos poblados residen menos de 16.500 personas en Madrid y 13.500 en Barcelona. No obstante, es importante subrayar la diferente superficie de los dos municipios estudiados: la de Madrid multiplica por seis la de Barcelona $\left(100 \mathrm{~km}^{2}\right)$, cuya superficie se asemeja más a la de la Almendra Central madrileña (unidad asociada al territorio ubicado en el interior de la vía de circunvalación M-30).

\subsection{La construcción del índice de gentrificación y las dimensiones sociodemográficas asociadas}

La comparabilidad de las transformaciones de carácter sociodemográfico entre Barcelona y Madrid es uno de los aspectos centrales de nuestra propuesta. La disponibilidad de datos nos permite enfatizar ese 
TABLA 2

RESUMEN DE LAS DIMENSIONES QUE COMPONEN EL ÍNDICE DE GENTRIFICACIÓN

\begin{tabular}{|l|l|l|}
\hline \multicolumn{1}{|c|}{ Dimensión } & \multicolumn{1}{|c|}{ Fecha de referencia y fuente estadística } & \multicolumn{1}{c|}{ Indicador } \\
\hline Estructura por edad & $\begin{array}{l}\text { Datos de stock con fecha a 1-I-2011 y 1-I-2019. Estadística del } \\
\text { Padrón Continuo }\end{array}$ & Porcentaje de población nacida entre 1974 y 1999 (\%) \\
\hline Origen & $\begin{array}{l}\text { Datos de stock con fecha a 1-I-2011 y 1-I-2019. Estadística del } \\
\text { Padrón Continuo }\end{array}$ & $\begin{array}{l}\text { Porcentaje de población nacida en países con un Índice de } \\
\text { Desarrollo Humano (IDH) superior a 0,825 (\%) }\end{array}$ \\
\hline Condición socioeconómica & $\begin{array}{l}\text { Datos de flujos. Dos periodos, 2011-12 y 2017-18. Registros } \\
\text { de altas y bajas del Padrón Municipal }\end{array}$ & $\begin{array}{l}\text { Porcentaje de entradas ( } \geq 25 \text { años) con estudios } \\
\text { universitarios (\%). }\end{array}$ \\
\hline Estructura del hogar & $\begin{array}{l}\text { Datos de stock con fecha a 1-I-2011 y 1-I-2019. Lectura } \\
\text { municipal del Padrón Continuo (hogar) }\end{array}$ & $\begin{array}{l}\text { Porcentaje de hogares unipersonales de adultos (18-64 años) } \\
\text { respecto al total de hogares (\%) }\end{array}$ \\
\hline Sustitución de la población & $\begin{array}{l}\text { Datos de flujos. Dos periodos, 2011-12 y 2017-18. Registros } \\
\text { de altas y bajas del Padrón Municipal }\end{array}$ & $\begin{array}{l}\text { Cociente entre el porcentaje de salidas sin estudios } \\
\text { universitarios y el porcentaje de entradas sin estudios } \\
\text { universitarios ( } \geq 25 \text { años) (\%) }\end{array}$ \\
\hline $\begin{array}{l}\text { Velocidad del cambio } \\
\text { poblacional }\end{array}$ & $\begin{array}{l}\text { Datos de flujos. Dos periodos, 2011-12 y 2017-18. Registros } \\
\text { de altas y bajas del Padrón Municipal }\end{array}$ & $\begin{array}{l}\text { Cociente entre las entradas con estudios universitarios y el } \\
\text { total de población ( } \geq 25 \text { años) (\%o) }\end{array}$ \\
\hline
\end{tabular}

Fuente: Elaboración propia.

aspecto y, por ese motivo, hemos calculado el índice de gentrificación de forma conjunta para las dos ciudades. Es decir, durante todo el proceso de construcción del indicador, la escala de intensidad estará marcada por los procesos que han experimentado los barrios de cualquiera de las dos ciudades. Así incidimos en la dimensión comparativa del índice, un rasgo poco frecuente en este tipo de aproximaciones (Easton, Lees, Hurbard y Tate, 2019).

Nuestro índice compuesto combina seis dimensiones conceptuales diferentes que están estrechamente asociadas con los cambios poblacionales que se experimentan en los sectores que la literatura ha descrito como gentrificados. Resumimos las fuentes, el tipo de observación y el indicador generado de cada una de las dimensiones en la Tabla 2.

En cada una de las seis dimensiones o ejes de transformación introducimos dos elementos de observación para el cálculo: (i) la diferencia, en puntos porcentuales, del indicador utilizado entre el inicio y el final del periodo (diferencia) y (ii) el nivel que alcanza al final del periodo (nivel). Consideramos, pues, que el indicador final debe reflejar tanto las transformaciones que se han experimentado a lo largo de la década como la intensidad con la que se experimenta cada dimensión específica. Los valores (tanto los correspondientes a la diferencia como al nivel) de cada una de las dimensiones se han normalizado en una escala de 0 a 1 . Se ha realizado una interpolación lineal entre los 190 valores de los barrios considerando como extremos de la distribución los quintos valores más altos y más bajos. Esta última decisión se ha tomado con el objetivo de minimizar el efecto de los valores más extremos y así conseguir una mayor dispersión entre los valores interpolados. Por tanto, los cinco valores más bajos de cada dimensión (tanto de diferencia como de nivel) puntúan 0 , y los cinco más altos puntúan 1. El resto de barrios obtienen un valor entre 0 y 1 . Como nuestro objetivo es el de generar un indicador que principalmente capte los procesos que se han desarrollado a lo largo del periodo de análisis, hemos optado por darle un mayor peso al valor de la diferencia y ponderamos doblemente ese valor (por tanto, ponderamos por $2 / 3$ la diferencia y $1 / 3$ el nivel). Una vez realizada la ponderación de los valores referentes a la diferencia y al nivel alcanzado en cada barrio, volvemos a normalizar en una escala de 0 a 1 , esta vez tomando como extremos los valores mínimos y máximos de la distribución. Finalmente, el índice compuesto de gentrificación multiplica con el mismo peso el indicador de cada una de las dimensiones (por tanto, 1/6). En la Tabla 3 presentamos los valores extremos y la mediana de las diferencias y de los niveles alcanzados en las seis dimensiones contempladas.

Asimismo, hemos calculado el índice de gentrificación de forma separada para cada ciudad. Hemos seguido el mismo procedimiento que el anterior, pero esta vez, la normalización de los valores observados de cada dimensión ha tomado los segundos valores extremos en Barcelona y los terceros en Madrid. Este cálculo específico nos permitirá observar diferencias en la relación de cada dimensión con el índice de gentrificación en las dos ciudades analizadas.

Finalmente, y con el objetivo de analizar las principales propiedades estadísticas del índice de gentrificación generado, hemos realizado un Análisis de 
TABLA 3

VALORES EXTREMOS Y MEDIANA DE LAS SEIS DIMENSIONES DEL ÍNDICE DE GENTRIFICACIÓN

\begin{tabular}{|c|c|c|c|c|c|c|c|c|c|c|c|c|}
\hline & \multicolumn{2}{|c|}{ Estructura por edad. } & \multicolumn{2}{|c|}{ Origen } & \multicolumn{2}{|c|}{ Condición socioeconóm. } & \multicolumn{2}{|c|}{ Estructura del hogar } & \multicolumn{2}{|c|}{ Sustitución } & \multicolumn{2}{|c|}{ Velocidad } \\
\hline & $\begin{array}{l}\text { Dif. } \\
\text { (p.p.) }\end{array}$ & $\begin{array}{l}\text { Nivel } \\
\text { (\%) }\end{array}$ & $\begin{array}{c}\text { Dif. } \\
\text { (p.p.) }\end{array}$ & $\begin{array}{c}\text { Nivel } \\
\text { (\%) }\end{array}$ & $\begin{array}{l}\text { Dif. } \\
\text { (p.p.) }\end{array}$ & $\begin{array}{l}\text { Nivel } \\
\text { (\%) }\end{array}$ & $\begin{array}{l}\text { Dif. } \\
\text { (p.p.) }\end{array}$ & $\begin{array}{c}\text { Nivel } \\
\text { (\%) }\end{array}$ & $\begin{array}{l}\text { Dif. } \\
\text { (p.) }\end{array}$ & $\begin{array}{c}\text { Nivel } \\
\text { (rat) }\end{array}$ & $\begin{array}{c}\text { Dif. } \\
\text { (p.m.) }\end{array}$ & $\begin{array}{l}\text { Nivel } \\
\text { (\%o) }\end{array}$ \\
\hline 50 valor + alto & 10,10 & 48,73 & 3,43 & 13,48 & 18,10 & 72,72 & 3,77 & 37,39 & 0,14 & 1,28 & 22,86 & 87,25 \\
\hline Mediana & 2,90 & 34,55 & $-0,03$ & 3,71 & 9,56 & 46,72 & 0,71 & 16,22 & 0,03 & 1,09 & 9,75 & 41,22 \\
\hline 5ㅇvalor + bajo & $-2,42$ & 28,20 & $-0,85$ & 1,34 & 1,51 & 15,47 & $-2,62$ & 9,76 & $-0,14$ & 0,97 & $-1,62$ & 13,17 \\
\hline
\end{tabular}

Fuente: Elaboración propia. Notas: Dif= Diferencias entre el valor a final de periodo menos a comienzo de periodo; Nivel = Indicador al final de periodo; $(p . p)=$ puntos porcentuales; $($ rat $)=$ ratio; $(p)=$. puntos de diferencia en la ratio; $(p . m)=$. puntos por mil.

Componentes Principales (ACP) con variación ortogonal varimax. EI ACP es una técnica ampliamente utilizada para reducir la dimensionalidad en una base de datos con diferentes variables, preservando la mayor variabilidad posible (Jolliffe y Cadima., 2016). En nuestro caso, además, utilizamos el ACP para identificar las dimensiones que contribuyen de forma más sustantiva al primer componente del ACP. Asimismo, podremos comparar la contribución de las diferentes dimensiones en Barcelona y en Madrid, lo que nos permitirá desvelar el papel que juegan en los procesos de gentrificación de cada ciudad. Para asegurarnos que se cumplían las condiciones para realizar el ACP hemos realizado una matriz de correlaciones de Spearman con las seis dimensiones utilizadas en el índice. Además, hemos utilizado otros dos tests para evaluar la aplicabilidad del ACP: 1) test de Esfericidad de Barlett, con un valor de significación estadística del 5\%; y 2) test de Kaiser-MeyerOlkin (KMO) para evaluar la adecuación muestral, tanto de la base de datos completa como de cada una de las dimensiones. Para concluir, hemos realizado un Análisis de Conglomerados Jerárquico (ACJ) con el método de Ward sobre el primer componente del ACP que nos permite agrupar barrios con rasgos comunes y valorar la similitud con los conglomerados obtenidos con nuestro índice (Peña, 2002). Los análisis se han realizado tanto para las dos ciudades en conjunto, como por separado.

\section{RESULTADOS}

4.1. Patrones territoriales de las dimensiones sociodemográficas asociadas a los procesos de gentrificación

En este apartado presentamos los patrones territoriales de cada una de las seis dimensiones que componen el índice de gentrificación. Lo hacemos a partir de un triple eje de análisis. En primer lugar, presentamos las cuatro dimensiones que están asociadas con cambios en cuatro características sociodemográficas específicas. En segundo lugar, introducimos la dimensión que refleja el proceso de sustitución de la población y acabamos con la dimensión de la velocidad de la transformación. A partir de este ejercicio se pueden identificar qué fenómenos sociodemográficos predominan en los procesos de gentrificación de Barcelona y Madrid, cómo se expanden en el territorio, así como rasgos distintivos en la forma en la que cada una de las dimensiones se manifiestan en los barrios.

\subsubsection{Dimensiones asociadas al cambio en la compo- sición de la población}

La primera dimensión que analizamos es la estructura por edad. Los espacios que viven procesos de gentrificación experimentan, generalmente, un crecimiento de la población adulta-joven (Moss, Revington, Wilkin, y Andrey, 2019). En el caso español, no obstante, es muy importante considerar el efecto del paso de las generaciones llenas (nacidas aproximadamente entre 1960-1975) por la vida adulta. Como éstas no se distribuyen aleatoriamente en los diferentes barrios de ambas ciudades, no comparamos un mismo grupo de edad en dos cortes transversales, sino que seguimos la evolución de las cohortes nacidas entre 1974 y 1999 (que cumplieron 45 años y 20 años en 2019, respectivamente) en los dos momentos analizados: 1-I-2011 y 1-I-2019. Presentamos la distribución territorial del nivel y de la diferencia de esta dimensión en la Figura 1.

En segundo lugar, el origen de la población ha sido incluido frecuentemente en los índices de gentrificación. En el caso español, y a diferencia del contexto anglosajón, apostamos por medir la variación de la población procedente de países con ingresos altos, en vez de los bajos. Justificamos este cambio por dos motivos. Por un lado, la migración internacional de baja cualificación en España es relativamente reciente, con lo que el abandono 
FIGURA 1

REJUVENECIMIENTO DE LA POBLACIÓN EN LOS BARRIOS DE BARCELONA Y MADRID.

A. Porcentaje de población nacida entre 1974 y 1999 (\%). 1-I-2019

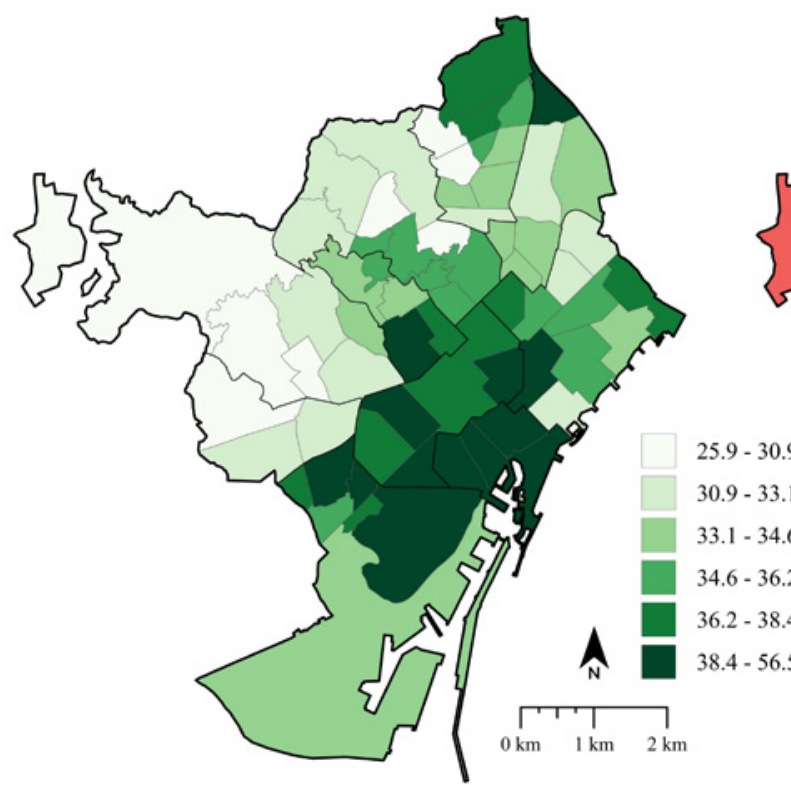

A. Porcentaje de población nacida entre 1974 y 1999 (\%). 1-I-2019
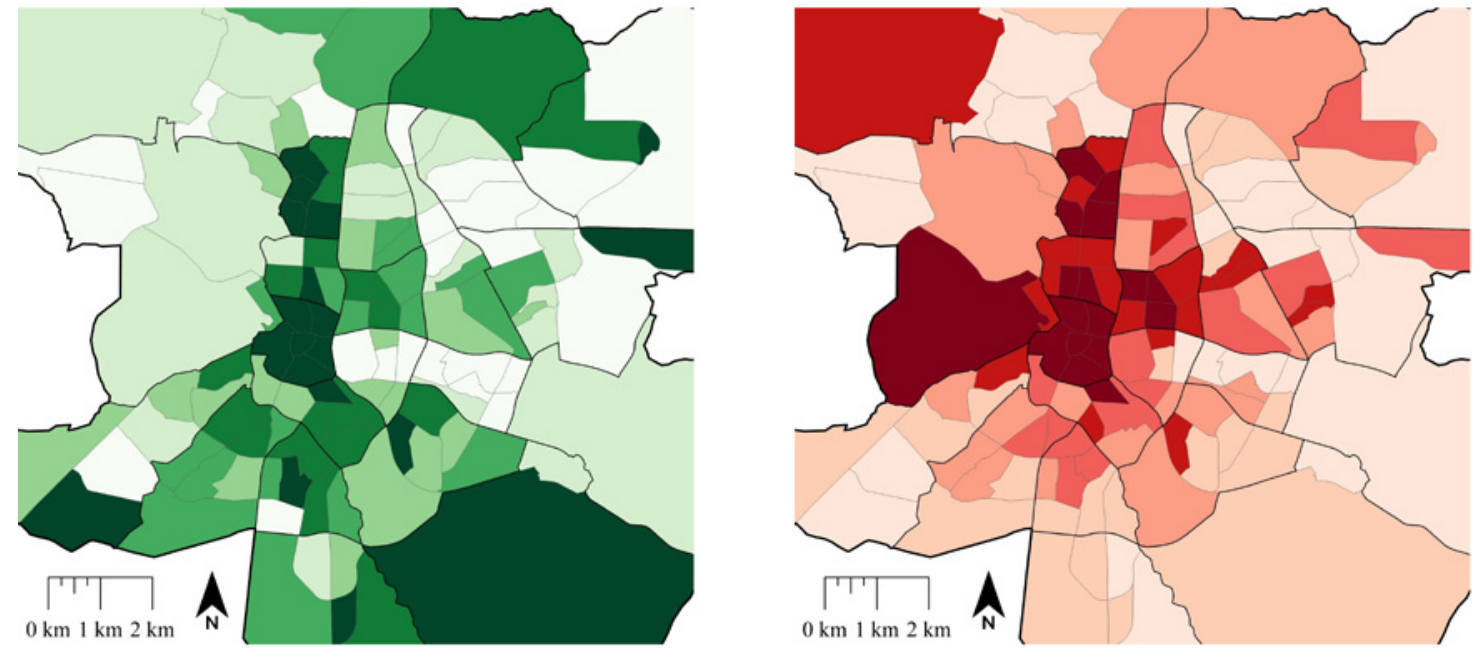

Fuente: Elaboración propia. Estadística del Padrón Continuo, Instituto Nacional de Estadística.

de determinados barrios no tiene por qué denotar un desplazamiento o una expulsión del lugar de residencia, sino que puede obedecer al propio proceso de asentamiento en la metrópolis (Bayona y López-Gay, 2011). Además, durante el periodo de crisis económica (2008-2014, aproximadamente) la evolución de este colectivo ha estado especialmente afectada por la migración de retorno o la re-emigración. Por el otro lado, la literatura apunta a que los procesos de gentrificación en el contexto del sur de Europa están cada vez más ligados a la llegada de población internacional muy cualificada, que además es cada vez más móvil (López-Gay et al., 2020). Como la Estadística del Padrón Continuo no ofrece ninguna variable socioeconómica de la población de origen extranjero, nos aproximamos a esta dimensión utilizando la clasificación del Índice de Desarrollo Humano (IDH) de la ONU, e incluimos a la población nacida en los 47 países con un IDH superior a 0,825 en 2018. La distribución 


\section{FIGURA 2}

ORIGEN DE LA POBLACIÓN EN LOS BARRIOS DE BARCELONA Y MADRID.

A. Porcentaje de población nacida en países con un IDH superior a 0,825 (\%) 1-I-2019
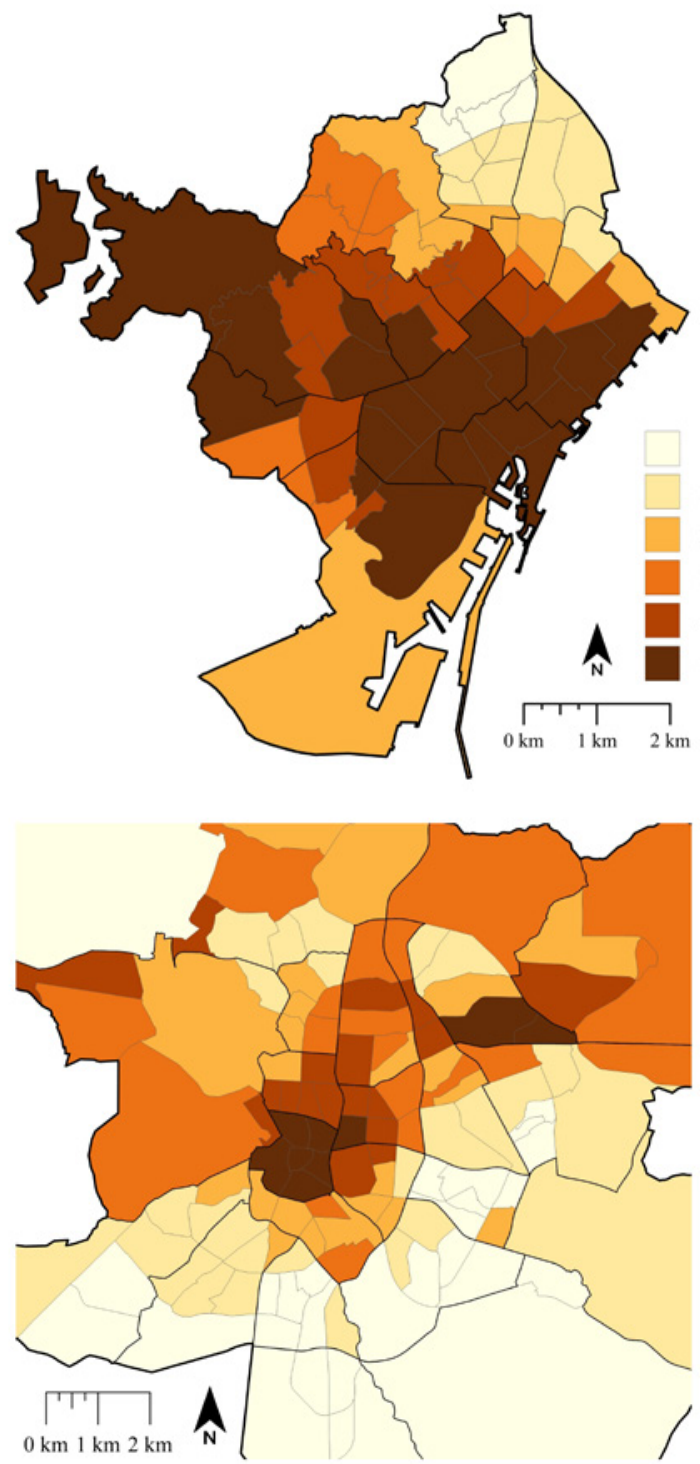

B. Diferencia (en puntos porcentuales) entre el porcentaje de población nacida en países con un IDH superior a 0,825 a 1-I-2019 y a 1-I-2011
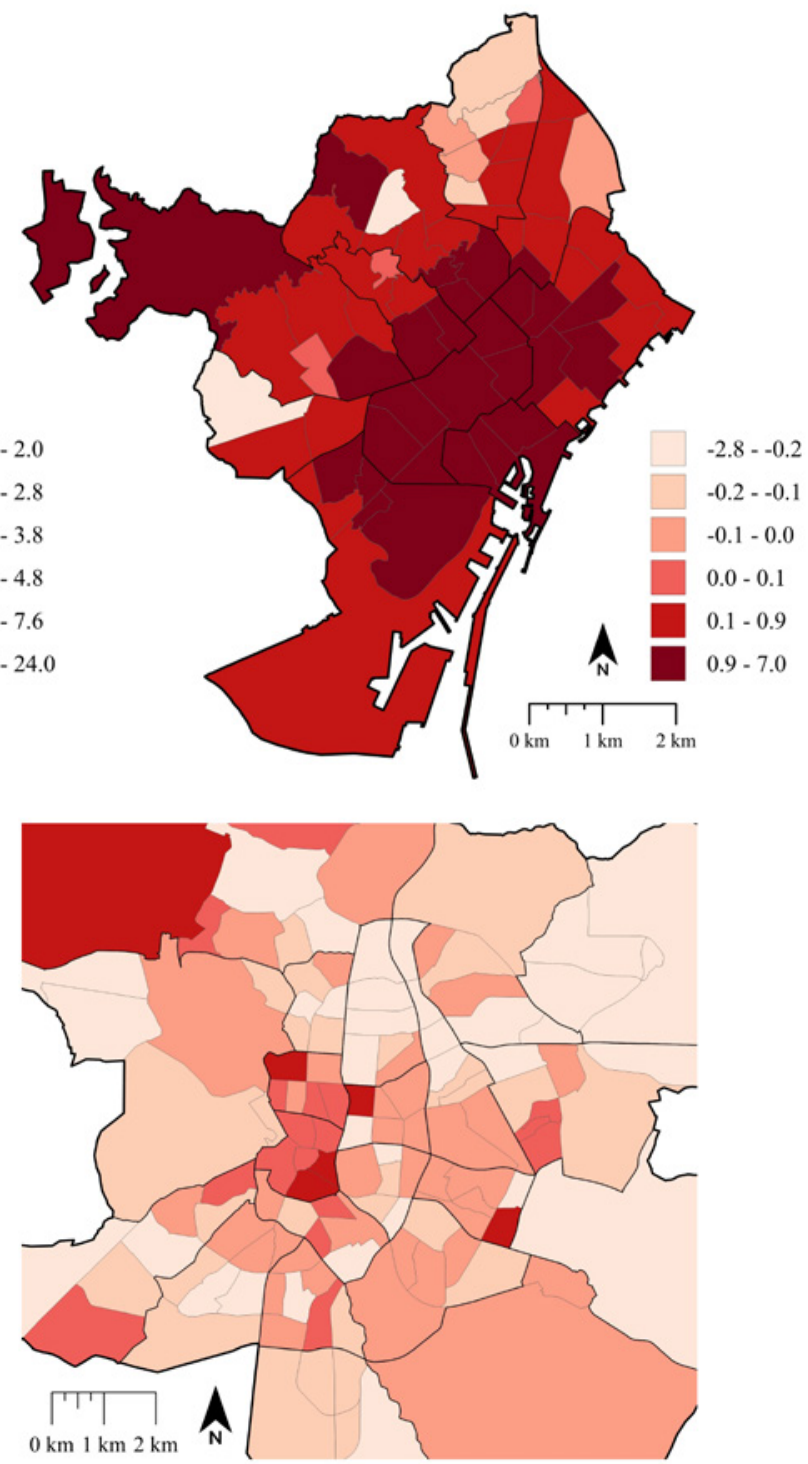

Fuente: Elaboración propia. Estadística del Padrón Continuo, Instituto Nacional de Estadística.

territorial del nivel y de la diferencia se presenta en la Figura 2.

En tercer lugar, es recurrente en los índices de gentrificación incluir la atracción de población con estudios universitarios (Atkinson et al., 2011). Esta dimensión la medimos a través de los flujos migratorios y residenciales registrados en el padrón continuo, que además permite superar la clásica limitación de la lectura transversal del padrón continuo español, asociada con la dificultad de actualizar el nivel de instrucción de la población que no cambia de residencia. La Figura 3 presenta el porcentaje de llegadas a cada barrio (sea desde otros barrios de la ciudad o desde fuera del municipio) de personas con estudios universitarios respecto al total de llegadas (de la población de más de 25 años), además del cambio entre los dos años al inicio y final del periodo estudiado. 
A. Porcentaje de entradas ( $\geq 25$ años) con estudios universitarios (\%) 1-I-2019
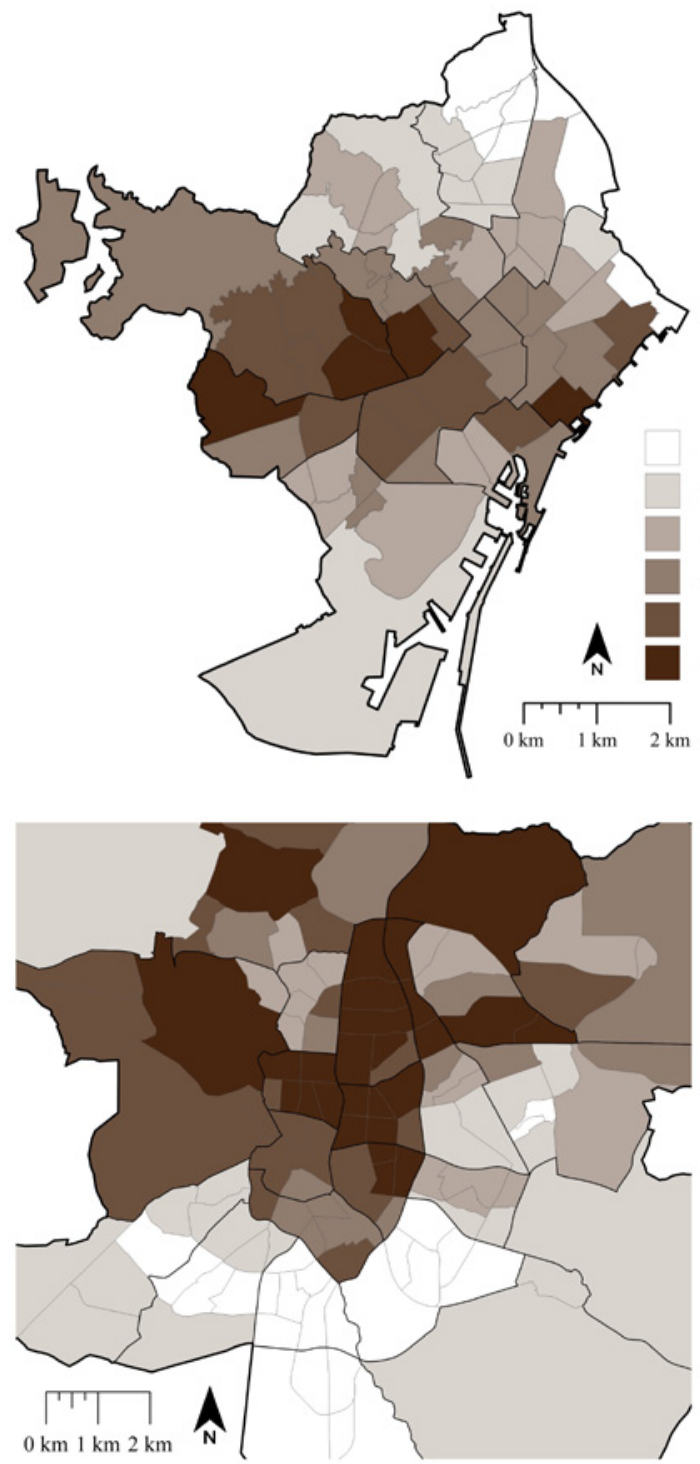

B. Diferencia (en puntos porcentuales) entre el porcentaje de entradas ( $\geq 25$ años) con estudios universitarios a 1-I-2019 y a 1-I-2011

Fuente: Elaboración propia. Registros de altas y bajas del Padrón Municipal por cambio de domicilio y migración. Ayuntamientos de Barcelona y Madrid.

Finalmente, desde la geografía de la población y la demografía se ha enfatizado la importancia de las transformaciones asociadas a las estructuras de los hogares en los barrios que se han gentrificado (Hall, Ogden y Hill, 1997). Estos cambios están vinculados a menudo a la llegada de población con nuevos comportamientos en la forma de convivencia, asociados a nuevos valores individuales y colectivos, y sintetizados en la teoría de la Segunda Transición Demográ- fica (Buzar, Ogden y Hall, 2005). La elevada presencia de hogares unipersonales, de parejas sin hijos (y que viven fuera del matrimonio) o de hogares extensos no familiares (pisos compartidos) es más común en los barrios que se han gentrificado. De todos estos tipos de hogares, la lectura municipal del padrón solo permite identificar a los hogares unipersonales, que son los que incluimos en nuestro indicador y presentamos en la Figura 4. 
FIGURA 4

HOGARES UNIPERSONALES EN LOS BARRIOS DE BARCELONA Y MADRID.

A. Porcentaje de hogares unipersonales (\%) 1-I-2019
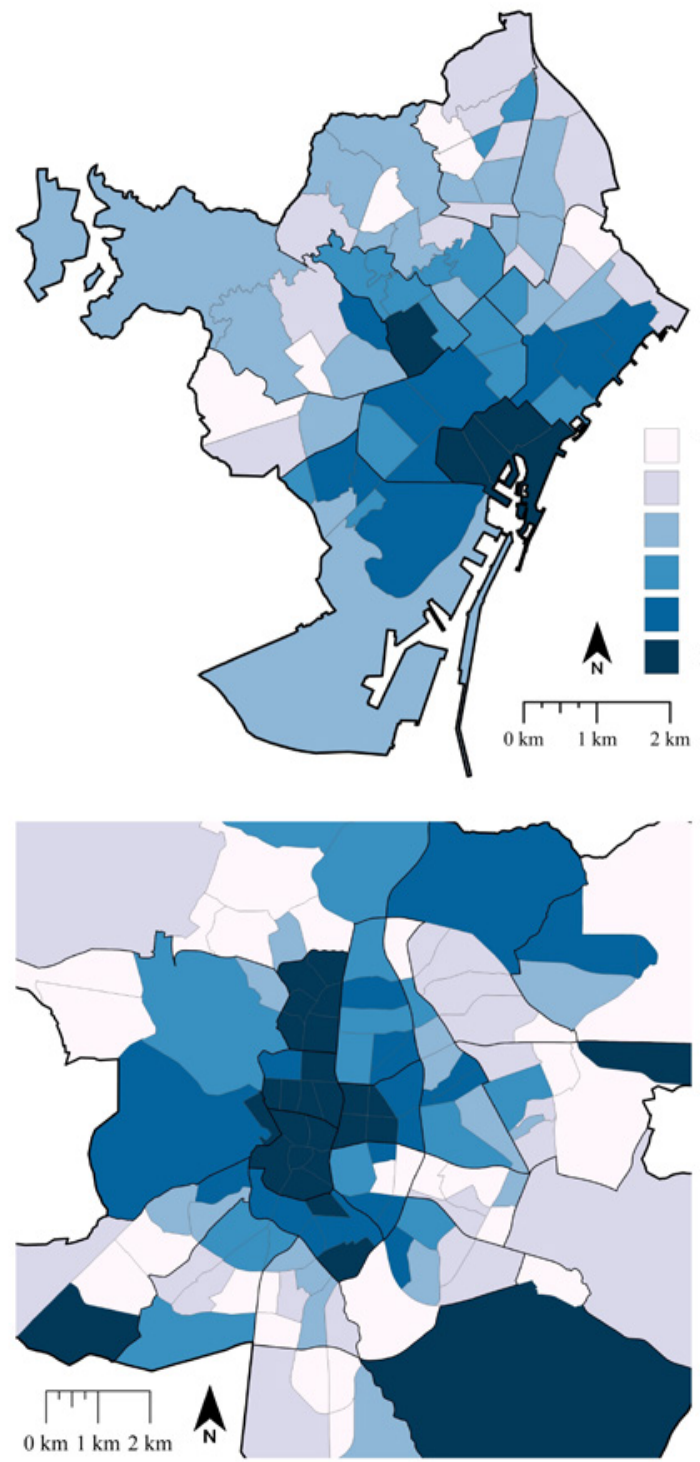

B. Diferencia (en puntos porcentuales) entre el porcentaje de hogares unipersonales a 1-I-2019 y a $1-\mid-2011$
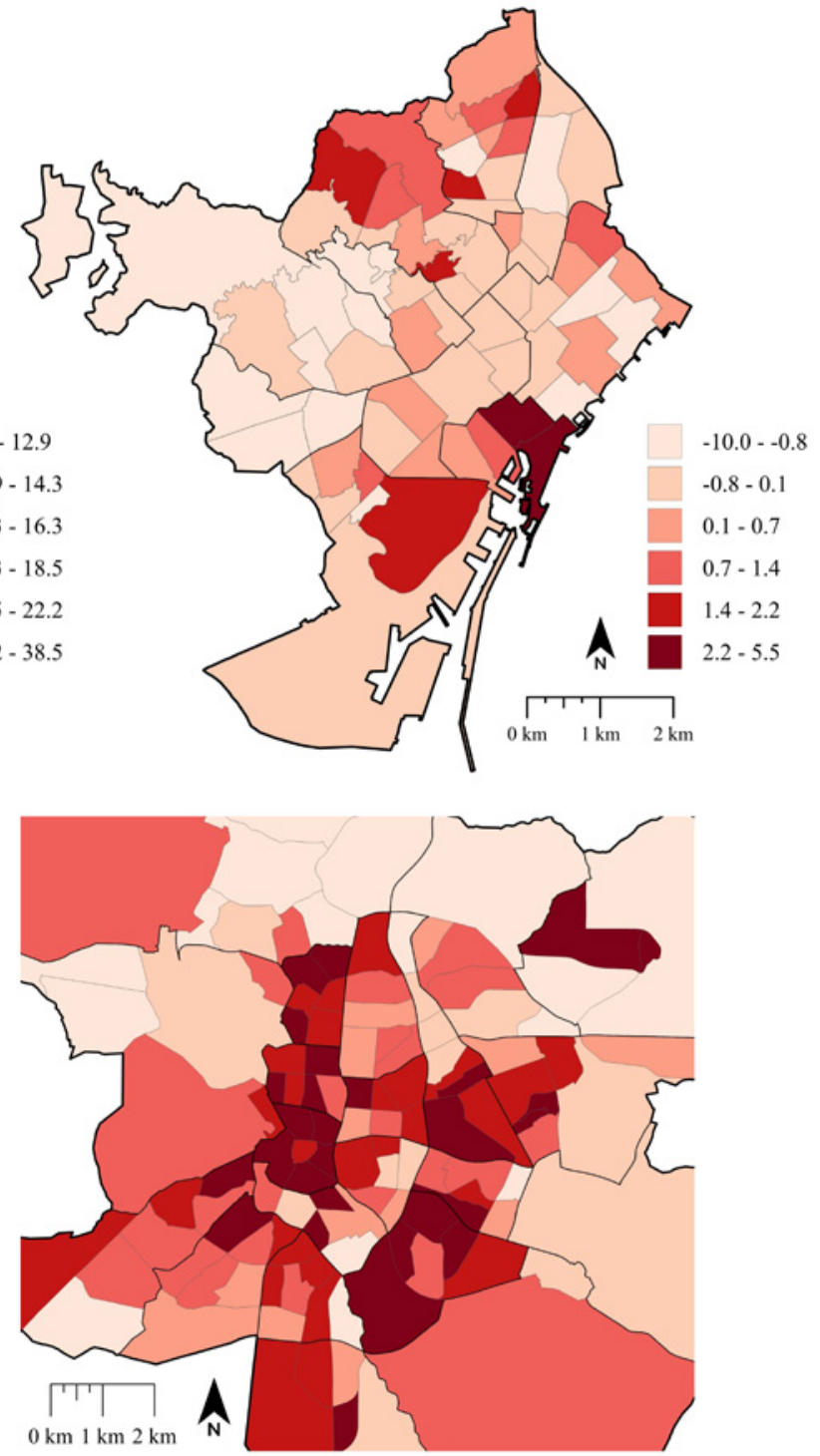

Fuente: Elaboración propia. lectura municipal del Padrón Continuo a nivel de hogar. Ayuntamientos de Barcelona y Madrid.

\subsubsection{La dimensión asociada a la sustitución de la población}

La medición de los procesos de desplazamiento y expulsión de la población ha sido el gran talón de Aquiles en los estudios cuantitativos de la gentrificación por su abordaje complejo (Easton et al., 2020). En este trabajo nos aproximamos a esta dimensión incidiendo en los procesos de sustitución de la pobla- ción. Incorporamos en el análisis las características de las personas que abandonan los barrios y las comparamos con las de personas que llegan. En este caso, situamos el foco en la población con menos capacidad económica, de la que la literatura nos dice que debería ir en retroceso en los barrios gentrificados (Ley, 1986). Aquí tomamos como referencia a la población sin estudios universitarios, dada la fuerte relación entre condición socioeconómica y nivel académico (Ru- 
SUSTITUCIÓN DE LA POBLACIÓN EN LOS BARRIOS DE BARCELONA Y MADRID.

A. Porcentaje de salidas sin estudios universitarios dividido por el porcentaje de entradas sin estudios universitarios ( $\geq 25$ años) (\%) 1-I-2019

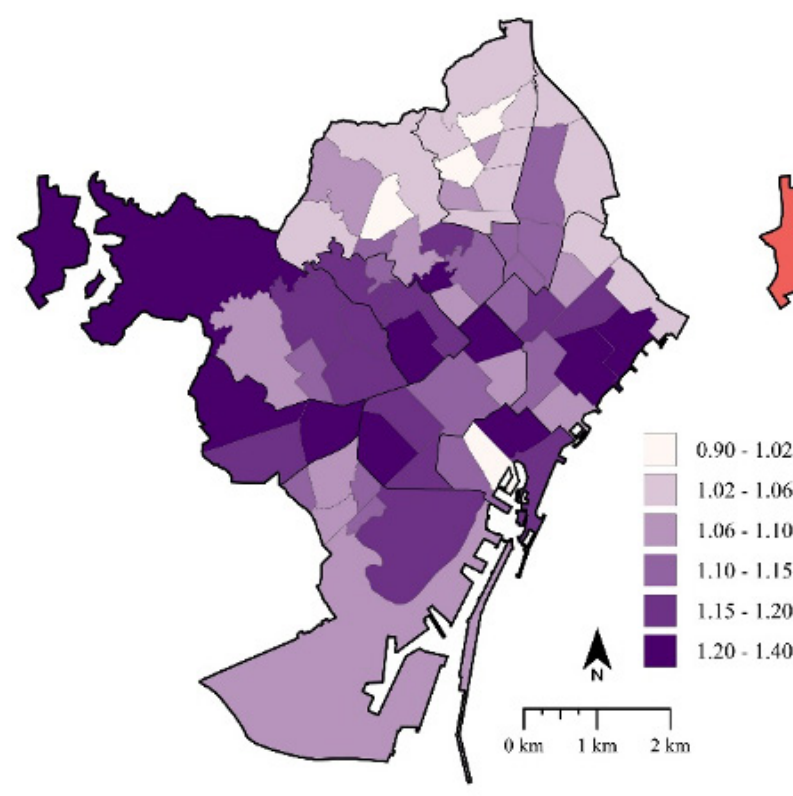

B. Diferencia (en puntos porcentuales) entre el porcentaje de salidas sin estudios universitarios dividido por el porcentaje de entradas sin estudios universitarios ( $\geq 25$ años) a 1-I-2019 y a 1-I-2011
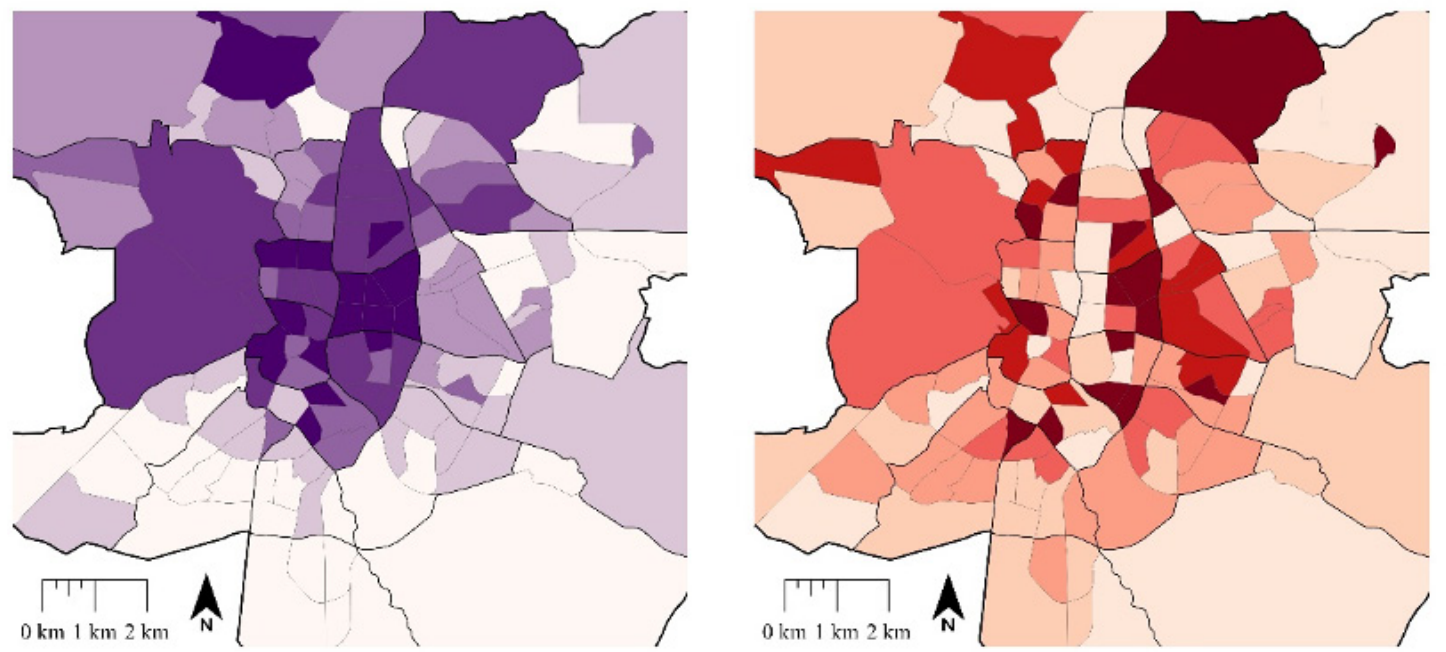

Fuente: Elaboración propia. Registros de altas y bajas del Padrón Municipal por cambio de domicilio y migración. Ayuntamientos de Barcelona y Madrid.

biales, 2017). Los barrios en los que las personas sin estudios universitarios están más representadas en los flujos de salida que en los de entrada están experimentando una paulatina sustitución de la población a favor de los más educados. En la Figura 5 representamos una ratio que es más elevada cuanto mayor es la presencia de personas sin estudios universitarios en los flujos de salida en comparación con los de entrada.

\subsubsection{La dimensión asociada a la velocidad del cam- bio poblacional}

La composición de los flujos por sí misma es insuficiente para medir los procesos de cambio sociodemográfico. Estas dinámicas están fuertemente determinadas por la intensidad de los flujos migratorios y residenciales, que repercuten directamente en la velocidad a la que se experimentan los cambios en 


\section{FIGURA 6}

VELOCIDAD DEL CAMBIO POBLACIONAL EN LOS BARRIOS DE BARCELONA Y MADRID.

A. Entradas con estudios universitarios divididas por el total de población ( $\geq 25$ años) (\%o)
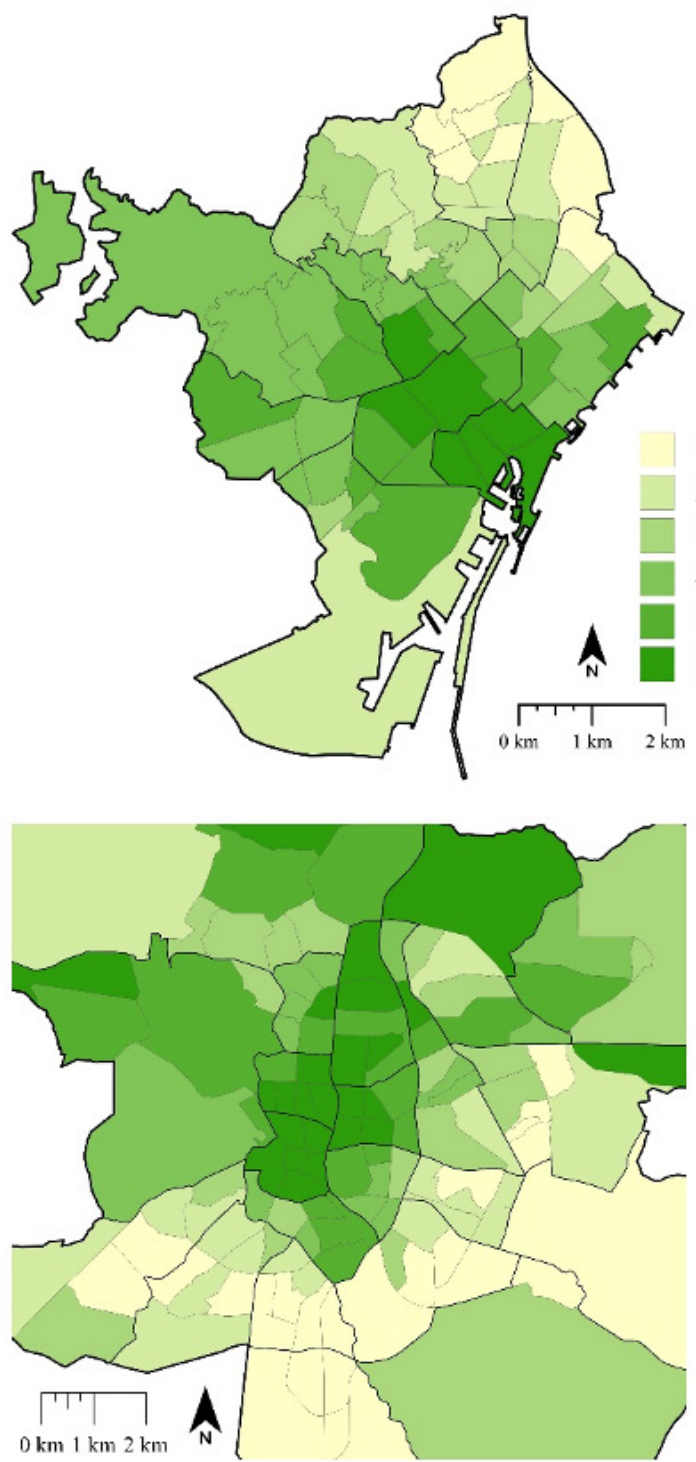

B. Diferencia (en puntos porcentuales) entre las entradas con estudios universitarios divididas por el total de población ( $\geq 25$ años) (\%o) a 1-I-2019 y a $1-\mid-2011$
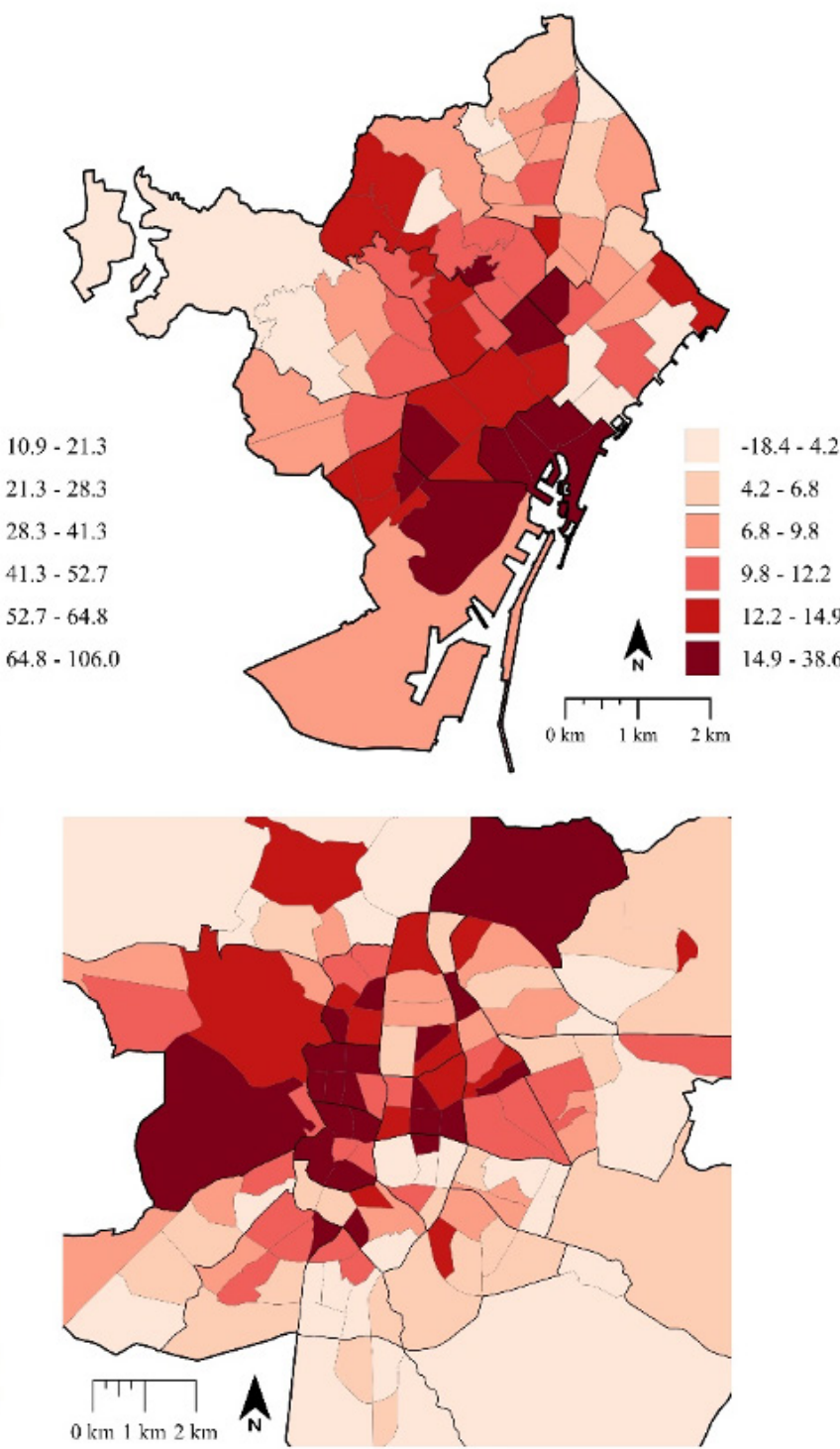

Fuente: Elaboración propia. Registros de altas y bajas del Padrón Municipal por cambio de domicilio y migración. Ayuntamientos de Barcelona y Madrid y Estadística del Padrón Continuo, Instituto Nacional de Estadística.

la composición de la población. En los barrios en los que avanza la gentrificación, la velocidad a la que se produce el proceso es alta y va en aumento (Rérat y Lees, 2011). En el contexto urbano español, y sobre todo en las dos ciudades analizadas, existe una fuerte heterogeneidad espacial de la velocidad a la que se transforman los barrios, tal y como se observa en la Figura 6, y que suele estar muy asociada al régi- men de tenencia de la vivienda. En esta dimensión nos limitamos a recoger la intensidad de llegada a cada barrio de la población más formada, para así captar los procesos de rotación asociados a la entrada de estos grupos y excluir otros movimientos de asentamiento en la ciudad que se producen a alta velocidad pero que no son afines a los procesos de gentrificación. 


\subsection{El índice de gentrificación, 2011-2019}

\subsubsection{Principales características del índice de gentri- ficación}

El índice compuesto de gentrificación se construye a partir de las seis dimensiones presentadas, y nos proporciona valores entre 0 y 1 para los 190 barrios incluidos en el análisis. El valor 1 lo habría obtenido aquel barrio que liderase cada una de las seis dimensiones contempladas y que corresponden a transformaciones asociadas a los procesos de gentrificación. Al contrario, el valor 0 lo habría obtenido el barrio a la cola de todas estas transformaciones. A partir del valor obtenido en el índice de gentrificación, hemos construido cuatro categorías. Debido a que no existe ningún elemento teórico que nos permita delimitar el nivel exacto a partir del cual podemos hablar de gentrificación, hemos etiquetado como barrios en proceso de gentrificación aquellos que se encuentran dentro del primer cuartil (1C) de la distribución. Dentro de este cuartil, consideramos oportuno diferenciar los barrios en dos categorías según el nivel de elitización que presentaba al inicio del periodo estudiado. Entre todas las variables que utilizamos, consideramos que la variable más oportuna para captar este aspecto es el porcentaje de personas con estudios universitarios que llegó al barrio en 2011 y 2012. Hemos delimitado como barrios previamente elitizados aquellos que están por encima del segundo quintil, es decir aquellas unidades con el $40 \%$ de valores más altos (en este caso, aquellos barrios en los que más del $43,25 \%$ de las personas que han llegado tenían estudios universitarios), a partir de ahora denominados "barrios previamente elitizados". Así pues, la primera categoría incluye los barrios en el primer cuartil del índice de gentrificación y que previamente estaban elitizados. La segunda categoría incluye barrios del primer cuartil en el índice de gentrificación pero que no estaban previamente elitizados. Los barrios que se encuentran dentro del segundo cuartil los hemos agrupado en una tercera categoría, cuyos valores nos apuntan hacia una ligera tendencia gentrificadora entre 2011 y 2019. Finalmente, la cuarta categoría incluye los 95 barrios de ambas ciudades con el índice de gentrificación más bajo (que corresponden al tercer y cuarto cuartil).

Los resultados del índice de gentrificación para cada uno de los barrios se presentan en la Figura 7 y en la Tabla 4, en la que también se incorporan los resultados que el índice de gentrificación obtendría si se analizasen las dos ciudades de forma independiente.
Según nuestro índice, Sant Pere, Santa Caterina i la Ribera, en el distrito barcelonés de Ciutat Vella, es el barrio que más transformaciones sociodemográficas afines a los procesos de gentrificación ha experimentado entre 2011 y 2019 cuando analizamos conjuntamente Barcelona y Madrid. El índice supera el 0,85 , un valor que también se alcanza en la Barceloneta, y que refleja una puntuación muy alta en todas las dimensiones analizadas. El barrio madrileño que puntúa más alto es Universidad, situado en el distrito Centro y cuyos límites territoriales se asocian al sector de Malasaña. El Raval, el Poble Sec y Hostrafrancs, en los distritos de Ciutat Vella y Sants-Montjuïc de Barcelona, y los barrios de Cortes, Justicia, Trafalgar y Embajadores en los distritos Centro y Chamberí de Madrid completan el listado de los diez barrios con un índice de gentrificación más elevado.

Tal y como hemos apuntado en el apartado metodológico, realizamos diferentes ejercicios para evaluar las características estadísticas del índice propuesto. El test de esfericidad de Barlett fue altamente significativo, lo que indicaría que hay homogeneidad de varianzas y por tanto se podía realizar el Análisis de Componentes Principales (ACP). El test de KMO ha concluido con un valor de 0,65 para la muestra en su conjunto, lo que indica que las condiciones para hacer el ACP son mínimamente adecuadas. Sin embargo, al analizar las dimensiones, la dimensión hogares unipersonales presenta un valor de 0,48 que se consideraría como no adecuado. El primer componente del ACP explica un $57 \%$ de la varianza total, un valor que refleja la naturaleza unidimensional del índice. La dimensión que menos contribuye ese primer componente del ACP es la de hogares unipersonales. Las tres dimensiones que más contribuyen son: velocidad de los procesos de transformación; rejuvenecimiento y atracción de la población cualificada. En la Tabla 5 mostramos el porcentaje de contribución de las distintas dimensiones al primer componente del ACP. En el Anexo 2 se puede consultar el clustering jerárquico agrupado en tres conglomerados, que refleja la similitud con la propuesta teórica de nuestro índice.

Hemos replicado el mismo ejercicio para los índices de gentrificación específicos de Barcelona y de Madrid. En el caso barcelonés, el test de esfericidad de Barlett también es altamente significativo. El test de KMO ofreció un valor de 0,63 para la muestra en su conjunto. Del mismo modo que ha sucedido en el análisis conjunto, la dimensión de hogares unipersonales presenta valores bajos $(0,41)$. El primer componente del ACP en Barcelona explica un 57,48\% de la varianza 
FIGURA 7

ÍNDICE DE GENTRIFICACIÓN EN BARCELONA Y MADRID.

\section{Índice de Gentrificación 2011-2019}

C1: Gentrificando (elitizado en 2011) C1: Gentrificando (no elitizado en 2011)

$\mathrm{C} 2$ : Ligera tendencia gentrificadora C3 + C4: Sin dinámicas gentrificadoras
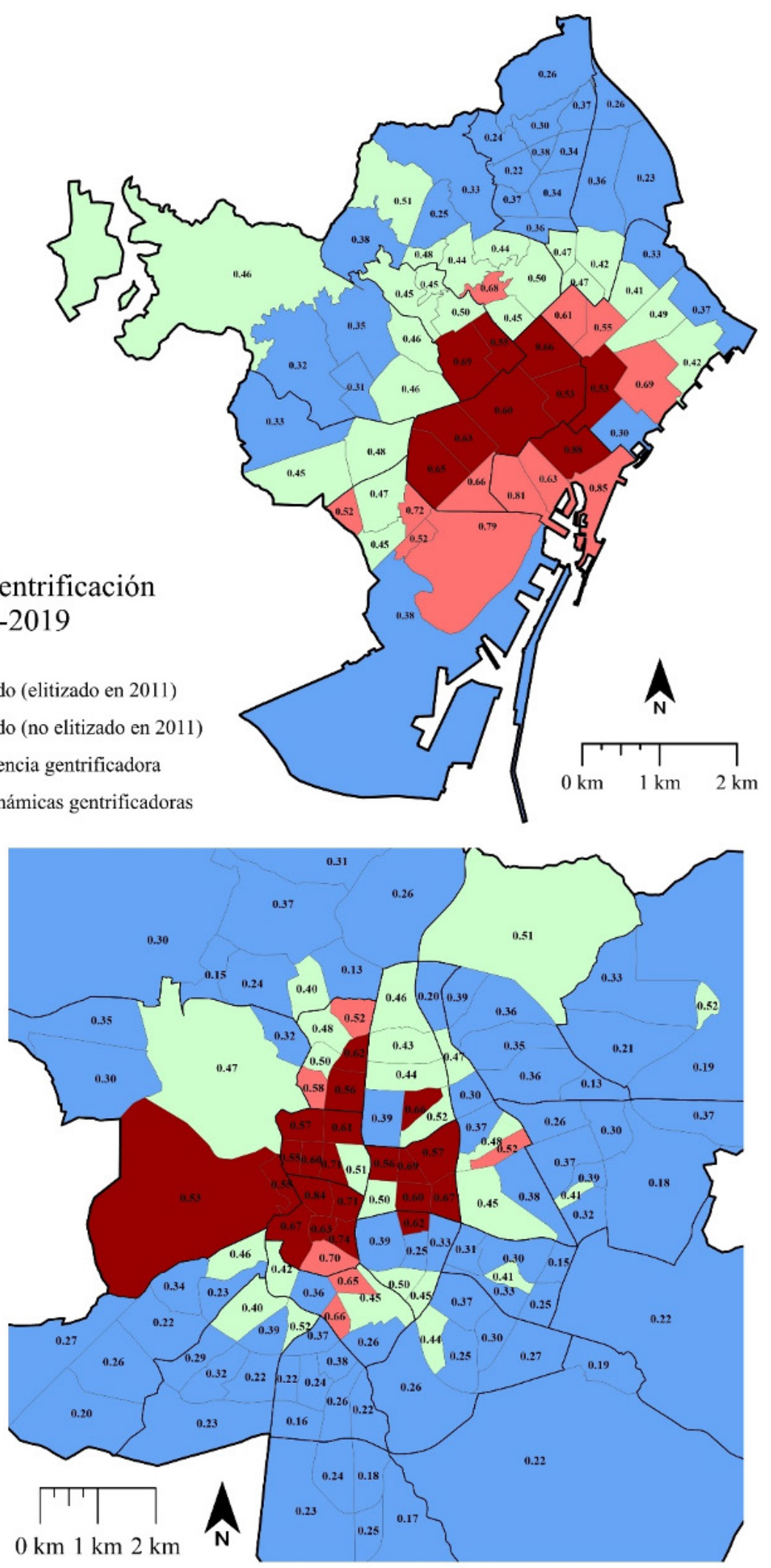
TABLA 4

RESULTADOS DEL ÍNDICE DE GENTRIFICACIÓN

\begin{tabular}{|c|c|c|c|c|c|c|c|c|c|c|c|c|c|}
\hline \# & Ciudad & Distrito & Barrio & IG (cat.) & IG-BCN & IG-MAD & \# & Ciudad & Distrito & Barrio & IG (cat.) & IG-BCN & IG-MAD \\
\hline 1 & $\mathrm{BCN}$ & Ciutat Vella & $\begin{array}{l}\text { Sant Pere, Santa Caterina i } \\
\text { la Ribera }\end{array}$ & $0,883(1)$ & $0,869(1)$ & - & 52 & $\mathrm{BCN}$ & Horta-Guinardó & Montbau & $0,511(3)$ & $0,432(3)$ & - \\
\hline 2 & $\mathrm{BCN}$ & Ciutat Vella & la Barceloneta & $0,855(2)$ & $0,858(1)$ & - & 53 & MAD & Chamberí & Almagro & $0,51(3)$ & - & $0,595(1)$ \\
\hline 3 & MAD & Centro & Universidad & $0,837(1)$ & - & $0,915(1)$ & 54 & MAD & Hortaleza & Valdefuentes & $0,507(3)$ & - & $0,567(3)$ \\
\hline 4 & $\mathrm{BCN}$ & Ciutat Vella & el Raval & $0,81(2)$ & $0,726(2)$ & - & 55 & MAD $S$ & Salamanca & Recoletos & $0,501(3)$ & - & $0,543(3)$ \\
\hline 5 & $\mathrm{BCN}$ & Sants-Montjuïc & el Poble Sec - Parc Montjuïc & $0,789(2)$ & $0,722(2)$ & - & 56 & $\mathrm{BCN}$ & Gràcia & la Salut & $0,5(3)$ & $0,44(3)$ & - \\
\hline 6 & MAD & Centro & Cortes & $0,741(1)$ & - & $0,852(1)$ & 57 & $\mathrm{BCN}$ & Horta-Guinardó & el Guinardó & $0,5(3)$ & $0,44(3)$ & - \\
\hline 7 & $\mathrm{BCN}$ & Sants-Montjuïc & Hostafrancs & $0,72(2)$ & $0,653(2)$ & - & 58 & MAD F & Retiro & Pacífico & $0,497(3)$ & - & $0,566(3)$ \\
\hline 8 & MAD & Centro & Justicia & $0,707(1)$ & - & $0,788(1)$ & 59 & MAD & Tetuán & Berruguete & $0,495(3)$ & - & $0,558(3)$ \\
\hline 9 & MAD & Chamberí & Trafalgar & $0,706(1)$ & - & $0,786(1)$ & 60 & $B C N S$ & Sant Martí & Provençals del Poblenou & $0,492(3)$ & $0,427(3)$ & - \\
\hline 10 & MAD & Centro & Embajadores & $0,702(2)$ & - & $0,813(2)$ & 61 & MAD & Tetuán & Valdeacederas & $0,485(3)$ & - & $0,558(3)$ \\
\hline 11 & $\mathrm{BCN}$ & Sant Martí & el Poblenou & $0,695(2)$ & $0,628(1)$ & - & 62 & $\mathrm{BCN}$ & Horta-Guinardó & la Teixonera & $0,479(3)$ & $0,429(3)$ & - \\
\hline 12 & MAD & Salamanca & Lista & $0,693(1)$ & - & $0,765(1)$ & 63 & MAD & Ciudad Lineal & Concepción & $0,479(3)$ & - & $0,547(3)$ \\
\hline 13 & $\mathrm{BCN}$ & Gràcia & la Vila de Gràcia & $0,69(1)$ & $0,598(1)$ & - & 64 & $\mathrm{BCN}$ & Les Corts & les Corts & $0,477(3)$ & $0,433(3)$ & - \\
\hline 14 & $\mathrm{BCN}$ & Horta-Guinardó & Can Baró & $0,684(2)$ & $0,638(2)$ & - & 65 & $\mathrm{BCN} S$ & Sants-Montjuïc & Sants & $0,474(3)$ & $0,388(4)$ & - \\
\hline 15 & MAD & Centro & Palacio & $0,668(1)$ & - & $0,756(1)$ & 66 & BCN S & Sant Andreu & el Congrés i els Indians & $0,474(3)$ & $0,413(3)$ & - \\
\hline 16 & MAD & Salamanca & Fuente del Berro & $0,667(1)$ & - & $0,737(1)$ & 67 & BCN S & Sant Andreu & Navas & $0,471(3)$ & $0,409(3)$ & - \\
\hline $\begin{array}{l}17 \\
18\end{array}$ & $\begin{array}{l}\text { MAD } \\
B C N\end{array}$ & Chamartín & $\begin{array}{l}\text { Ciudad Jardín } \\
\text { Sant Antoni }\end{array}$ & $\begin{array}{l}0,662(1) \\
0,661(2)\end{array}$ & 0,589 & $0,709(1)$ & 68 & MAD & $\begin{array}{l}\text { Moncloa - } \\
\text { Aravaca }\end{array}$ & Ciudad Universitaria & $0,468(3)$ & - & $0,543(3)$ \\
\hline 18 & $\begin{array}{l}\text { BCN } \\
\text { MAD }\end{array}$ & $\begin{array}{l}\text { Eixample } \\
\text { Arganzuela }\end{array}$ & $\begin{array}{l}\text { Sant Antonı } \\
\text { Chopera }\end{array}$ & $0,658(2)$ & $\begin{array}{r}0,589 \\
-\end{array}$ & $0,719(2)$ & 69 & MAD & Ciudad Lineal & Colina + Atalaya & $0,466(3)$ & - & $0,489(3)$ \\
\hline 20 & $\mathrm{BCN}$ & Eixample & la Sagrada Família & $0,657(1)$ & $0,587(1)$ & - & 70 & $\mathrm{BCN}$ & $\begin{array}{l}\text { Sarrià-Sant } \\
\text { Gervasi }\end{array}$ & Sant Gervasi - Galvany & $0,465(3)$ & $0,389(4)$ & - \\
\hline 21 & MAD & Arganzuela & Palos de Moguer & $0,647(2)$ & & $0,733(2)$ & 71 & MAD L & Latina & Puerta del Ángel & $0,464(3)$ & - & $0,55(3)$ \\
\hline 22 & $\mathrm{BCN}$ & Eixample & $\begin{array}{l}\text { la Nova Esquerra de } \\
\text { l'Eixample }\end{array}$ & $0,645(1)$ & $0,584(1)$ & - & 72 & $\mathrm{BCN}$ & $\begin{array}{l}\text { Sarrià-Sant } \\
\text { Gervasi }\end{array}$ & el Putxet i el Farró & $0,459(3)$ & 0,394 (3) & - \\
\hline 23 & $\mathrm{BCN}$ & Ciutat Vella & el Barri Gòtic & $0,633(2)$ & $0,606(1)$ & - & 73 & MAD & Chamartín & Castilla & $0,459(3)$ & - & $0,518(3)$ \\
\hline 24 & $\mathrm{BCN}$ & Eixample & $\begin{array}{l}\text { l'Antiga Esquerra de } \\
\text { I'Eixample }\end{array}$ & $0,628(1)$ & $0,529(1)$ & - & 74 & $\mathrm{BCN}$ & $\begin{array}{l}\text { Sarrià-Sant } \\
\text { Gervasi }\end{array}$ & $\begin{array}{l}\text { Vallvidrera, el Tibidabo i } \\
\text { les Planes }\end{array}$ & $0,458(3)$ & $0,347(4)$ & - \\
\hline 25 & MAD & Centro & Sol & $0,627(1)$ & - & $0,724(1)$ & 75 & $\mathrm{BCN}$ & Gràcia & el Coll & $0,453(3)$ & $0,394(3)$ & - \\
\hline 26 & MAD & Tetuán & Castillejos & $0,62(1)$ & - & $0,681(1)$ & 76 & MAD F & Retiro & Adelfas & $0,45(3)$ & - & $0,511(3)$ \\
\hline 27 & MAD & Retiro & Ibiza & $0,616(1)$ & - & $0,674(1)$ & 77 & MAD & Ciudad Lineal & Ventas & $0,45(3)$ & - & $0,522(3)$ \\
\hline 28 & $\mathrm{BCN}$ & Sant Martí & el Camp de l'Arpa del Clot & $0,608(2)$ & $0,529(2)$ & - & 78 & $\mathrm{BCN}$ & Horta-Guinardó & el Baix Guinardó & $0,449(3)$ & $0,373(4)$ & - \\
\hline 29 & MAD & Chamberí & Ríos Rosas & $0,606(1)$ & - & $0,679(1)$ & 79 & $\mathrm{BCN} S$ & Sants-Montjuïc & la Bordeta & $0,448(3)$ & $0,383(4)$ & - \\
\hline 30 & MAD & Salamanca & Goya & $0,603(1)$ & - & $0,677(1)$ & 80 & MAD A & Arganzuela & Delicias + Atocha & $0,447(3)$ & - & $0,524(3)$ \\
\hline 31 & $\mathrm{BCN}$ & Eixample & la Dreta de l'Eixample & $0,598(1)$ & $0,472(3)$ & - & 81 & BCN L & Les Corts & la Maternitat i Sant Ramon & $0,446(3)$ & $0,401(3)$ & - \\
\hline 32 & MAD & Chamberí & Arapiles & $0,598(1)$ & - & $0,675(1)$ & 82 & $\mathrm{BCN}$ & Gràcia & Vallcarca i els Penitents & $0,446(3)$ & $0,371(4)$ & - \\
\hline $\begin{array}{l}33 \\
34\end{array}$ & $\begin{array}{l}\text { MAD } \\
\text { MAD }\end{array}$ & $\begin{array}{l}\text { Tetuán } \\
\text { Chamberí }\end{array}$ & $\begin{array}{l}\text { Bellas Vistas } \\
\text { Vallehermoso }\end{array}$ & $\begin{array}{l}0,584(2) \\
0,574(1)\end{array}$ & $\begin{array}{l}- \\
-\end{array}$ & $\begin{array}{l}0,653(2) \\
0,66(1)\end{array}$ & 83 & MAD & $\begin{array}{l}\text { Puente de } \\
\text { Vallecas }\end{array}$ & San Diego & $0,445(3)$ & - & $0,515(3)$ \\
\hline 35 & MAD & Salamanca & Guindalera & $0,568(1)$ & - & $0,636(1)$ & 84 & MAD & Chamartín & Hispanoamérica & $0,444(3)$ & - & $0,492(3)$ \\
\hline 36 & MAD & Tetuán & Cuatro Caminos & $0,561(1)$ & - & $0,631(2)$ & 85 & BCN & Horta-Guinardó & el Carmel & $0,44(3)$ & $0,376(4)$ & - \\
\hline 37 & MAD & Salamanca & Castellana & $0,556(1)$ & - & $0,665(1)$ & 86 & BCN & Horta-Guinardó & la Font d'en Fargues & $0,439(3)$ & 0,391 (3) & - \\
\hline 38 & MAD & Chamberí & Gaztambide & $0,554(1)$ & - & $0,633(1)$ & 87 & MAD C & Chamartín & Nueva España & $0,433(3)$ & - & $0,48(3)$ \\
\hline 39 & MAD & $\begin{array}{l}\text { Moncloa - } \\
\text { Aravaca }\end{array}$ & Argüelles & $0,554(1)$ & - & $0,624(1)$ & 88 & BCN S & Sant Martí & $\begin{array}{l}\text { Diagonal Mar i el Front } \\
\text { Marítim del Poblenou }\end{array}$ & $0,423(3)$ & $0,356(4)$ & - \\
\hline 40 & $\mathrm{BCN}$ & Gràcia & $\begin{array}{l}\text { el Camp d'en Grassot i } \\
\text { Gràcia Nova }\end{array}$ & $0,552(1)$ & $0,484(1)$ & - & 89 & $\begin{array}{l}B C N S \\
M A D A\end{array}$ & $\begin{array}{l}\text { Sant Andreu } \\
\text { Arganzuela }\end{array}$ & $\begin{array}{l}\text { la Sagrera } \\
\text { Imperial }\end{array}$ & $\begin{array}{l}0,419(3) \\
0,418(3)\end{array}$ & $\begin{array}{c}0,361(4) \\
-\end{array}$ & - \\
\hline 41 & $\mathrm{BCN}$ & Sant Martí & el Clot & $0,548(2)$ & $0,495(2)$ & - & 90 & MIAD & $\begin{array}{l}\text { Arganzuela } \\
\text { San Blas - }\end{array}$ & & & - & 3) \\
\hline 42 & $\mathrm{BCN}$ & Sant Martí & $\begin{array}{l}\text { el Parc i la Llacuna del } \\
\text { Poblenou }\end{array}$ & $0,529(1)$ & $0,443(3)$ & - & 91 & MAD & Canillejas & Amposta & $0,411(3)$ & - & $0,487(3)$ \\
\hline 43 & MAD & $\begin{array}{l}\text { Moncloa - } \\
\text { Aravaca }\end{array}$ & Casa de Campo & $0,529(1)$ & - & $0,595(2)$ & $\begin{array}{l}92 \\
93\end{array}$ & $\begin{array}{l}B C N S \\
\text { MAD }\end{array}$ & $\begin{array}{l}\text { Sant Martí } \\
\text { Moratalaz }\end{array}$ & $\begin{array}{l}\text { Sant Martí de Provençals } \\
\text { Vinateros }\end{array}$ & $\begin{array}{l}0,408(3) \\
0,406(3)\end{array}$ & $\begin{array}{c}0,347(4) \\
-\end{array}$ & $0,48(3)$ \\
\hline $\begin{array}{l}44 \\
45\end{array}$ & $\begin{array}{l}\mathrm{BCN} \\
\mathrm{BCN}\end{array}$ & $\begin{array}{l}\text { Eixample } \\
\text { Sants-Montjuïc }\end{array}$ & $\begin{array}{l}\text { el Fort Pienc } \\
\text { Sants - Badal }\end{array}$ & $\begin{array}{l}0,526(1) \\
0,524(2)\end{array}$ & $\begin{array}{l}0,409(3) \\
0,483(2)\end{array}$ & - & 94 & MAD & $\begin{array}{l}\text { Fuencarral - El } \\
\text { Pardo }\end{array}$ & Pilar & $0,403(3)$ & - & $0,472(3)$ \\
\hline 46 & MAD & Tetuán & Almenara & $0,524(2)$ & - & $0,601(2)$ & 95 & MAD C & Carabanchel & San I & $0,399(3)$ & - & $0,472(3)$ \\
\hline 47 & $\mathrm{BCN}$ & Sants-Montjuïc & la Font de la Guatlla & $0,523(2)$ & $0,452(3)$ & & 96 & MAD C & Carabanchel & Opañel & $0,394(4)$ & - & $0,465(3)$ \\
\hline 48 & MAD & Ciudad Lineal & Quintana & $0,519(2)$ & - & $0,582(2)$ & 97 & MAD C & Chamartín & El Viso & $0,393(4)$ & - & $0,452(3)$ \\
\hline 49 & MAD & Carabanchel & Comillas & 0,517 (3) & - & $0,59(2)$ & 98 & MAD & Hortaleza & Apóstol Santiago & $0,392(4)$ & - & $0,464(3)$ \\
\hline 50 & MAD & Barajas & Casco Histórico de Barajas & $0,516(3)$ & - & $0,576(2)$ & 99 & MAD & $\begin{array}{l}\text { San Blas - } \\
\text { Canillejas }\end{array}$ & Hellín & $0,392(4)$ & - & $0,47(3)$ \\
\hline 51 & MAD & Chamartín & Prosperidad & $0,515(3)$ & - & $0,584(1)$ & 100 & MAD F & Retiro & Los Jerónimos & $0,387(4)$ & - & $0,464(3)$ \\
\hline
\end{tabular}




\begin{tabular}{|c|c|c|c|c|c|c|c|c|c|c|c|c|c|}
\hline \# & Ciudad & Distrito & Barrio & IG (cat.) & IG-BCN & IG-MAD & \# & Ciudad & Distrito & Barrio & IG (cat.) & IG-BCN & IG-MAD \\
\hline 101 & $\mathrm{BCN}$ & Sants-Montjuïc & $\begin{array}{l}\text { la Marina del Prat Vermell } \\
\text { - Zona Franca + la Marina }\end{array}$ & $0,384(4)$ & $0,332(4)$ & - & 146 & MAD & $\begin{array}{l}\text { Puente de } \\
\text { Vallecas }\end{array}$ & Portazgo & $0,295(4)$ & - & $0,37(4)$ \\
\hline & & & de Port & & & & 147 & MAD & Carabanchel & Vista Alegre & $0,292(4)$ & - & $0,357(4)$ \\
\hline $\begin{array}{l}102 \\
103\end{array}$ & $\begin{array}{l}\text { MAD } \\
\text { MAD }\end{array}$ & $\begin{array}{l}\text { Ciudad Lineal } \\
\text { Usera }\end{array}$ & $\begin{array}{l}\text { Pueblo Nuevo } \\
\text { Almendrales }\end{array}$ & $\begin{array}{l}0,384(4) \\
0,383(4)\end{array}$ & $\begin{array}{l}- \\
-\end{array}$ & $\begin{array}{c}0,457(3) \\
0,46(3)\end{array}$ & 148 & MAD & $\begin{array}{l}\text { Puente de } \\
\text { Vallecas }\end{array}$ & Palomeras Sureste & $0,274(4)$ & - & $0,341(4)$ \\
\hline 104 & $\mathrm{BCN}$ & Nou Barris & Verdun & $0,382(4)$ & $0,313(4)$ & $m_{1}$ & 149 & MAD L & Latina & Campamento & $0,269(4)$ & - & $0,323(4)$ \\
\hline 105 & $\mathrm{BCN}$ & Horta-Guinardó & Sant Genís dels Agudells & $0,378(4)$ & $0,291(4)$ & - & 150 & $\mathrm{BCN} \mathrm{N}$ & Nou Barris & $\begin{array}{l}\text { Torre Baró + Ciutat } \\
\text { Meridiana + Vallbona }\end{array}$ & $0,265(4)$ & 0,194 (4) & - \\
\hline 106 & MAD & $\begin{array}{l}\text { San Blas - } \\
\text { Canillejas }\end{array}$ & Simancas & $0,374(4)$ & - & $0,437(3)$ & 151 & MAD & $\begin{array}{l}\text { Puente de } \\
\text { Vallecas }\end{array}$ & Entrevías & $0,262(4)$ & - & $0,333(4)$ \\
\hline 107 & $\mathrm{BCN}$ & Sant Martí & el Besòs i el Maresme & $0,373(4)$ & $0,294(4)$ & - & 152 & MAD L & Latina & Águilas & $0,259(4)$ & - & $0,326(4)$ \\
\hline 108 & MAD & $\begin{array}{l}\text { Fuencarral - El } \\
\text { Pardo }\end{array}$ & Mirasierra & $0,372(4)$ & - & $0,394(4)$ & 153 & MAD & $\begin{array}{l}\text { San Blas - } \\
\text { Canillejas }\end{array}$ & El Salvador & $0,258(4)$ & - & $0,307(4)$ \\
\hline 109 & MAD & Usera & Moscardó & $0,369(4)$ & - & $0,445(3)$ & 154 & MAD & Arganzuela & Legazpi & $0,256(4)$ & - & $0,281(4)$ \\
\hline 110 & MAD & $\begin{array}{l}\text { San Blas - } \\
\text { Canillejas }\end{array}$ & Rejas & $0,369(4)$ & - & $0,434(4)$ & 155 & MAD & $\begin{array}{l}\text { Fuencarral - El } \\
\text { Pardo }\end{array}$ & Valverde & $0,256(4)$ & - & $0,332(4)$ \\
\hline 111 & $\mathrm{BCN}$ & Nou Barris & la Trinitat Nova & $0,367(4)$ & $0,295(4)$ & - & 156 & $\mathrm{BCN} S$ & Sant Andreu & la Trinitat Vella & $0,255(4)$ & $0,176(4)$ & - \\
\hline 112 & MAD & $\begin{array}{l}\text { Puente de } \\
\text { Vallecas }\end{array}$ & Numancia & $0,366(4)$ & - & $0,434(4)$ & 157 & MAD & Usera & Orcasur & $0,255(4)$ & - & $0,336(4)$ \\
\hline 113 & $\mathrm{BCN}$ & Nou Barris & $\begin{array}{l}\text { el Turó de la Peira + Can } \\
\text { Peguera }\end{array}$ & $0,365(4)$ & $0,31(4)$ & - & 158 & MAD & Villaverde & San Cristóbal & $0,255(4)$ & - & $0,321(4)$ \\
\hline 114 & MAD & Ciudad Lineal & San Pascual & $0,365(4)$ & - & $0,427(4)$ & 159 & $\mathrm{BCN}$ & Horta-Guinardó & la Vall d'Heb & $253(4)$ & $33(4)$ & - \\
\hline 115 & $\mathrm{BCN}$ & Sant Andreu & Sant Andreu & $0,364(4)$ & $0,316(4)$ & - & 160 & MAD & Vallecas & Palomeras Bajas & $0,252(4)$ & - & $0,326(4)$ \\
\hline 116 & MAD & Hortaleza & Piovera & $0,363(4)$ & - & $0,375(4)$ & 161 & MAD N & Moratalaz & Pavones & $0,252(4)$ & - & $0,351(4)$ \\
\hline 117 & $\mathrm{BCN}$ & Nou Barris & Vilapicina i la Torre Llobeta & $0,36(4)$ & $0,295(4)$ & - & 162 & MAD F & Retiro & Niño Jesús & $0,249(4)$ & - & $0,315(4)$ \\
\hline 118 & MAD & Arganzuela & Acacias & $0,357(4)$ & - & $0,432(4)$ & 163 & MAD L & Usera & Pradolongo & $0,244(4)$ & - & $0,306(4)$ \\
\hline 119 & MAD & Hortaleza & Pinar del Rey & $0,357(4)$ & - & $0,42(4)$ & 164 & MAD & Villaverde & Ángeles & $0,243(4)$ & - & $0,309(4)$ \\
\hline 120 & $\mathrm{BCN}$ & $\begin{array}{l}\text { Sarrià-Sant } \\
\text { Gervasi }\end{array}$ & Sant Gervasi - la Bonanova & $0,354(4)$ & $0,272(4)$ & - & 165 & BCN & Nou Barris & Canyelles & $0,241(4)$ & $0,187(4)$ & - \\
\hline 121 & MAD & $\begin{array}{l}\text { Moncloa - } \\
\text { Aravaca }\end{array}$ & Valdemarín + El Plantío & $0,348(4)$ & - & $0,392(4)$ & 166 & MAD & $\begin{array}{l}\text { Fuencarral - El } \\
\text { Pardo }\end{array}$ & Peñagrande & $0,236(4)$ & - & $0,306(4)$ \\
\hline 122 & MAD & Hortaleza & Canillas & $0,345(4)$ & - & $0,419(4)$ & 167 & MAD & Carabanchel & Buenavista & $0,232(4)$ & - & $0,3(4)$ \\
\hline 123 & MAD & Latina & Lucero & $0,34(4)$ & - & $0,411(4)$ & 168 & MAD L & Latina & Los Cármenes & $0,23(4)$ & - & $0,301(4)$ \\
\hline 124 & $\mathrm{BCN}$ & Nou Barris & Porta & $0,337(4)$ & $0,244(4)$ & - & 169 & $\mathrm{BCN} S$ & Sant Andreu & $\begin{array}{l}\text { Baró de Viver + el Bon } \\
\text { Pastor }\end{array}$ & $0,227(4)$ & $0,15(4)$ & - \\
\hline 125 & $\mathrm{BCN}$ & Nou Barris & la Prosperitat & $0,336(4)$ & $0,268(4)$ & - & 170 & MAD & Villaverde & San Andrés & $0,226(4)$ & - & $0,292(4)$ \\
\hline 126 & $\mathrm{BCN}$ & Sant Martí & la Verneda i la Pau & $0,334(4)$ & $0,265(4)$ & - & 171 & MAD & Villa de Vallecas & $\begin{array}{l}\text { Casco Histórico de Vallecas } \\
\text { +Ensanche de Vallecas }\end{array}$ & $0,225(4)$ & - & $0,301(4)$ \\
\hline 127 & $\mathrm{BCN}$ & Les Corts & Pedralbes & $0,333(4)$ & $0,273(4)$ & - & & & & Casco Histórico de Vicálvaro & & & \\
\hline 128 & $\mathrm{BCN}$ & Horta-Guinardó & Horta & $0,331(4)$ & $0,25(4)$ & - & 172 & MAD & Vicálvaro & $\begin{array}{l}\text { + Valdebernardo + } \\
\text { Valderrivas + El Cañaveral }\end{array}$ & $0,223(4)$ & - & $0,281(4)$ \\
\hline 129 & MAD & Retiro & Estrella & $0,327(4)$ & - & $0,402(4)$ & 173 & $\mathrm{BCN}$ & Nou Barris & la Guineueta & $0,221(4)$ & $0,133(4)$ & - \\
\hline 130 & MAD & Moratalaz & Fontarrón & $0,327(4)$ & - & $0,402(4)$ & 174 & MAD L & Latina & Aluche & $0,221(4)$ & - & $0,278(4)$ \\
\hline 131 & MAD & Barajas & Timón & $0,326(4)$ & - & $0,38(4)$ & 175 & MAD L & Usera & San Fermín & $0,219(4)$ & - & $0,287(4)$ \\
\hline 132 & MAD & $\begin{array}{l}\text { San Blas - } \\
\text { Canillejas }\end{array}$ & Arcos & $0,322(4)$ & - & $0,399(4)$ & 176 & MAD & Carabanchel & Abrantes & $0,217(4)$ & - & $0,277(4)$ \\
\hline 133 & $\mathrm{BCN}$ & $\begin{array}{l}\text { Sarrià-Sant } \\
\text { Gervasi }\end{array}$ & Sarrià & $0,32(4)$ & $0,226(4)$ & - & 177 & MAD L & Usera & Zofío & $0,217(4)$ & - & $0,284(4)$ \\
\hline 134 & MAD & Moncloa - & Valdezarza & $0,32(4)$ & - & $0.39(4)$ & 178 & MAD & Barajas & Corralejos & $0,212(4)$ & - & $0,226(4)$ \\
\hline & & Aravaca & & & & |רו (דכנט & 179 & MAD L & Latina & Cuatro Vientos & $0,204(4)$ & - & $0,259(4)$ \\
\hline 135 & MAD & Carabanchel & Puerta Bonita & $0,319(4)$ & - & 0,3 & 180 & MAD & Ciudad Lineal & Costillares & $0,2(4)$ & - & $0,259(4)$ \\
\hline 136 & MAD & Moratalaz & Media Legua & $0,308(4)$ & - & $0,384(4)$ & 181 & MAD & Villa de Vallecas & Santa Eugenia & $0,19(4)$ & - & $0,257(4)$ \\
\hline 137 & $\mathrm{BCN}$ & $\begin{array}{l}\text { Sarrià-Sant } \\
\text { Gervasi }\end{array}$ & les Tres Torres & $0,306(4)$ & $0,231(4)$ & - & 182 & MAD E & Barajas & $\begin{array}{l}\text { Alameda de Osuna + } \\
\text { Aeropuerto }\end{array}$ & $0,186(4)$ & - & $0,228(4)$ \\
\hline 138 & MAD & $\begin{array}{l}\text { Fuencarral - El } \\
\text { Pardo }\end{array}$ & El Goloso & $0,306(4)$ & - & $0,367(4)$ & 183 & MAD & $\begin{array}{l}\text { San Blas - } \\
\text { Canillejas }\end{array}$ & Rosas & $0,183(4)$ & - & $0,251(4)$ \\
\hline 139 & MAD & Moratalaz & Marroquina & $0,305(4)$ & - & $0,38(4)$ & 184 & MAD & Villaverde & Los Rosales & $0,177(4)$ & - & $0,24(4)$ \\
\hline 140 & MAD & Ciudad Lineal & San Juan Bautista & $0,302(4)$ & - & $0,333(4)$ & 185 & MAD & Villaverde & Butarque & $0,168(4)$ & - & $0,227(4)$ \\
\hline 141 & $\mathrm{BCN}$ & Nou Barris & les Roquetes & $0,298(4)$ & $0,222(4)$ & - & 186 & MAD L & Usera & Orcasitas & $0,159(4)$ & - & $0,233(4)$ \\
\hline 142 & MAD & $\begin{array}{l}\text { Fuencarral - El } \\
\text { Pardo }\end{array}$ & El Pardo & $0,298(4)$ & - & $0,393(4)$ & 187 & MAD & $\begin{array}{l}\text { Fuencarral - El } \\
\text { Pardo }\end{array}$ & telarreina & $0,153(4)$ & - & $0,225(4)$ \\
\hline 143 & MAD & $\begin{array}{l}\text { San Blas - } \\
\text { Canillejas }\end{array}$ & Canillejas & $0,297(4)$ & - & $0,366(4)$ & 188 & MAD I & Moratalaz & Horcajo & $0,15(4)$ & - & $0,203(4)$ \\
\hline 144 & MAD & $\begin{array}{l}\text { Moncloa - } \\
\text { Aravaca }\end{array}$ & Aravaca & $0,296(4)$ & - & $0,353(4)$ & 189 & MAD & $\begin{array}{l}\text { Fuencarral - El } \\
\text { Pardo }\end{array}$ & La Paz & $0,131(4)$ & - & $0,177(4)$ \\
\hline 145 & $\mathrm{BCN}$ & Sant Martí & $\begin{array}{l}\text { la Vila Olímpica del } \\
\text { Poblenou }\end{array}$ & $0,295(4)$ & $0,19(4)$ & - & 190 & MAD & Hortaleza & Palomas & $0,126(4)$ & - & $0,133(4)$ \\
\hline
\end{tabular}

Fuente: Elaboración propia. Notas: Categorías: 1=1C (elitizado en 2011); 2=1C (no elitizado en 2011); 3=2C; 4=3C+4C. IG-BCN/MAD: resultados del ejercicio específico en cada ciudad. 
TABLA 5

CONTRIBUCIÓN PORCENTUAL DE LAS DIMENSIONES AL PRIMER COMPONENTE DEL ANÁLISIS DE COMPONENTES PRINCIPALES

\begin{tabular}{|l|c|c|c|}
\hline & Indicador de Gentrificación (IG conjunto) & IG Barcelona & \multicolumn{1}{|c|}{ IG Madrid } \\
\hline Estructura por edad & $20,55 \%$ & $21,08 \%$ & $15,04 \%$ \\
\hline Origen & $11,99 \%$ & $13,90 \%$ & $13,56 \%$ \\
\hline Condición socioeconómica & $18,23 \%$ & $11,50 \%$ & $18,52 \%$ \\
\hline Estructura del hogar & $8,60 \%$ & $5,86 \%$ & $15,67 \%$ \\
\hline Sustitución de la población & $15,85 \%$ & $24,28 \%$ & $22,15 \%$ \\
\hline Velocidad del cambio poblacional & $24,76 \%$ & \\
\hline
\end{tabular}

Fuente: Elaboración propia. Notas: Categorías: 1=1C (elitizado en 2011); $2=1 \mathrm{C}$ (no elitizado en 2011); 3=2C; 4=3C+4C. IG-BCN/MAD: resultados del ejercicio específico en cada ciudad.

total. La dimensión que menos ha contribuido a ese primer componente es la de sustitución de la población $(5,86 \%)$ y la que más velocidad de sustitución $(24,28 \%)$. Destaca, además, la dimensión del origen de la población, con un valor del $21 \%$. En el caso del índice estimado usando únicamente los barrios de Madrid, el test de esfericidad de Barlett también es altamente significativo. El test de KMO presenta un valor de 0,78 para la muestra en su conjunto, más alto que en Barcelona. En general, en Madrid, todas las dimensiones presentan valores de KMO aceptables. El primer componente del ACP en Madrid explica un $63,91 \%$ de la varianza total. A diferencia del caso barcelonés, la contribución de las diferentes dimensiones al primer componente es muy equilibrada, con una mínima contribución del 13,56\%, que corresponde a la dimensión origen, y una máxima del $22,15 \%$, de la dimensión velocidad de sustitución.

\subsubsection{El avance territorial de la gentrificación en Barcelona y Madrid}

Las transformaciones sociodemográficas afines a los procesos de gentrificación que se han experimentado en Barcelona y Madrid durante la década 2010 presentan numerosos puntos en común, aunque también algunas diferencias manifiestas. Los centros históricos de ambas ciudades se han consolidado a lo largo de la década como ámbitos en los que se superponen la mayor parte de cambios sociodemográficos atribuibles a los espacios gentrificados. Por un lado, y a diferencia de los patrones que se dibujaban a finales del siglo XX, la población adulta-joven tiene un peso muy notable, además de creciente, en la pirámide demográfica. En los cuatro barrios del distrito de Ciutat Vella, en Barcelona, la mitad de la población empadronada en 2019 ha nacido entre 1974 y 1999 y su presencia se ha incrementado en más de 10 puntos porcentuales a lo largo del periodo estudiado. En
Madrid se ha experimentado un crecimiento similar, aunque en ninguno de los barrios se supera el $50 \%$ de población de esas generaciones. Por otro lado, no hay otros barrios más allá de los situados en los centros históricos en los que se alcancen valores superiores de residentes nacidos en países de economías ricas, en nuestro caso con un Índice de Desarrollo Humano elevado. En el barrio de Sant Pere, Santa Caterina y la Ribera, en Barcelona, una de cada cuatro personas empadronadas ha nacido en un país extranjero con IDH alto, mientras que en el Barri Gòtic y en la Barceloneta, el porcentaje se sitúa alrededor del $20 \%$, y en otros 10 barrios, muchos de ellos próximos a la franja litoral, se supera el 10\%. En Madrid, el barrio con mayor presencia de este colectivo es Cortes, con un $13 \%$. En el caso de los hogares unipersonales, en cambio, hay una mayor presencia en los barrios del centro histórico madrileño. Allí, los hogares unipersonales de personas adultas representan entre un 33\% y un $39 \%$ de todos los hogares, mientras que los barrios de Ciutat Vella están por debajo del 30\%. Además, el crecimiento de este tipo de hogares durante la década ha sido más intenso en Madrid que en Barcelona, una tendencia que también se ha manifestado en ámbitos más alejados del centro, como por ejemplo en barrios del distrito de Tetuán o en Puerta del Ángel, en el distrito de Latina. Finalmente, la velocidad de los cambios poblacionales a favor de los grupos más educados es también una dimensión en la que los centros históricos de ambas ciudades presentan valores muy elevados. En estos ámbitos, por tanto, se manifiesta una notable rotación poblacional, en una dinámica que podría estar favorecida por el predominio del alquiler en el mercado residencial.

En las dos dimensiones restantes, tanto en la atracción de población cualificada como en la intensidad de los procesos de sustitución demográfica, son otros ámbitos de la ciudad, más allá de los centros históri- 
cos, los que lideran las transformaciones. Así, por lo que respecta a la primera, los barrios con mayores ingresos son los que atraen a una población más cualificada. Estos espacios corresponden a los barrios de los distritos Les Corts y Sarrià-Sant Gervasi en BarceIona, y a los de Salamanca y Chamberí en Madrid. En cambio, los barrios donde más se ha fortalecido la selección educativa de la nueva población residente se sitúan sobre todo alrededor de espacios tradicionalmente más elitizados. En barrios como Hostrafancs, Poble Sec, Can Baró, el Clot o el Poble Nou, en BarceIona, y Ciudad Jardín, Trafalgar, Casa de Campo, Chopera o Comillas, el porcentaje de llegadas con estudios universitarios ha aumentado en más de 15 puntos porcentuales a lo largo de la década. Finalmente, los procesos más intensos de sustitución poblacional que penalizan a los menos educados también se localizan en espacios que circundan a los sectores más céntricos. En este grupo aparecen tanto barrios compuestos tradicionalmente por población con rentas altas, como los del distrito de Salamanca, en Madrid, o Pedralbes, en Barcelona, como otros en los que se ha visto reforzada esa exclusividad, como Ciudad Jardín en Madrid o la Nova Esquerra de l'Eixample y el Poblenou, en Barcelona. Por lo que respecta a la evolución de esta dimensión durante la década, son sobre todo los barrios de esta última tipología, localizados en los márgenes de los ámbitos más exclusivos, los que registran las intensidades de cambio más notables.

El índice de gentrificación final nos ha permitido sintetizar los diferentes vectores de transformación sociodemográfica. Tomando como referencia el valor del índice hemos creado una categoría que engloba al $25 \%$ de barrios con los valores más elevados y la definimos como zonas que se han gentrificado durante la década. El número de barrios en esta primera categoría es similar en Barcelona y en Madrid (21 y 27 respectivamente) y dibujan una gran zona central de las que surgen ramificaciones, con características propias en cada caso. En Barcelona, todos los barrios de los distritos de Ciutat Vella y del Eixample se incluyen en esta categoría. En el caso del Eixample, todos los barrios menos Sant Antoni ya estaban fuertemente elitizados en 2011, mientras que en Ciutat Vella, el Raval, el Gòtic y la Barceloneta partían de bajos niveles de elitización. Todos los barrios alrededor de este sector central, a excepción de la Vila Olímpica del Poblenou, aparecen con valores elevados de gentrificación, algunos de los cuales ya estaban fuertemente elitizados en 2011, como la Vila de Gràcia o el Camp del Grassot i la Gràcia Nova, mientras que otros muestran una transformación mucho más reciente, como el Poble
Sec, Hostafrancs, el Poblenou y el Camp de l'Arpa del Clot. Algo más alejados del sector central aparecen los barrios de Can Baró, Sants-Badal y la Font de la GuatIla, con un proceso de gentrificación más incipiente. En Madrid, todos los barrios del distrito Centro alcanzan valores altos, una zona que se expande hacia el norte (la práctica totalidad de barrios del distrito de Chamberí, y los orientales de Tetuán) y hacia el noreste (barrios del distrito de Salamanca y los del sureste de Chamartín, además de Quintana en Ciudad Lineal). Al sur, los barrios de Palos de Moguer y Chopera, en el distrito de Arganzuela, alcanzan valores muy elevados del índice de gentrificación. Además, dentro del grupo de barrios con procesos de gentrificación son los que al inicio de la década presentaban una menor elitización, junto a Embajadores, al sur del distrito Centro y en cuyo territorio se encuentra Lavapies.

Los barrios con valores del índice de gentrificación correspondientes al segundo cuartil de la distribución los hemos definido como zonas con ligera tendencia gentrificadora. Estos barrios presentan una mayor estabilidad sociodemográfica, pero registran valores elevados en algunos vectores de cambio. Este sería el caso de los barrios situados en el entorno del Guinardó, así como el de los barrios de la Teixonera, Vallcarca, la Salut, Navas, Provençals de Poblenou o les Corts. Más alejados del centro de la ciudad encontramos los barrios de Montbau y de Vallvidrera, el Tibidabo i les Planes. En Madrid, la mayor parte de barrios que corresponden a esta categoría se sitúan en el interior de la Almendra Central, pero se identifican barrios que manifiestan la existencia de ligeras dinámicas asociadas a la gentrificación al otro lado de la frontera que conforma la M-30. Puerta del Ángel, en Latina y Comillas en Carabanchel, parecen ser los barrios por los que penetran los procesos de gentrificación hacia los distritos del sur de Madrid. Al este y al noreste, Concepción en Ciudad Lineal y Valdefuentes en Hortaleza, también presentan notables valores del índice de gentrificación.

Finalmente, los barrios del tercer y cuarto cuartil de la distribución los hemos definido como barrios sin dinámicas gentrificadoras. Es esta una categoría heterogénea, que incluye tanto a barrios de rentas muy altas como de rentas bajas, pero que se asemejan entre sí por presentar bajos niveles de transformación en todas las dimensiones que hemos contemplado y por registrar una fuerte estabilidad sociodemográfica. En Barcelona, encontramos barrios con residentes de ingresos altos, como Pedralbes, Sarrià o les Tres Torres, así como otros de renta baja, 
sobre todo situados en el distrito de Nou Barris y al norte del de Sant Andreu. En Madrid, la situación es similar a la de Barcelona, y observamos tanto a los barrios exclusivos del norte de la ciudad, como los de rentas más bajas situados al sur.

\section{DISCUSIÓN}

Hacer frente a las causas y a los efectos derivados de los procesos de gentrificación es uno de los principales retos a los que están haciendo frente las dos ciudades más pobladas de España, Madrid y Barcelona (Gomà, 2018). Como en muchas otras áreas urbanas del mundo, preocupa la transformación del espacio urbano, el acceso a la vivienda, la inseguridad residencial y el cambio en la composición de la población, que favorece a los estratos socioeconómicos más privilegiados a través del desplazamiento de los más vulnerables, que estarían marchándose hacia espacios más periféricos (Bailey y Milton, 2018; Hochstebanch y Musterd, 2021). Por ese motivo, emergen acciones y políticas públicas que tienen como objetivo frenar, o al menos mitigar, estas dinámicas. Ahora bien, pese a esos avances en la esfera de la acción política, la gentrificación es todavía un proceso difícilmente cuantificable y por eso su diagnosis ha sido tradicionalmente compleja (Atkinson y Wulff, 2009). En este artículo hemos querido dar un paso en esa dirección y hemos propuesto un índice para medir la intensidad con la que se han manifestado esos procesos en la última década, así como para localizar los espacios en los que se han experimentado y observar sus pautas de irrupción y expansión en el territorio. Basándonos en aportaciones teóricas y experiencias cuantitativas internacionales hemos generado un índice que engloba hasta seis dimensiones, todas ellas de naturaleza sociodemográfica. Los aspectos más innovadores de esta propuesta son la utilización de diversas fuentes de información, entre las que destaca el uso pionero de la composición de los flujos migratorios y residenciales, auténticos motores de los cambios poblacionales, y la comparabilidad de los resultados entre Barcelona y Madrid, al haber aplicado una metodología conjunta que incluye a todos los barrios de ambas ciudades.

El análisis que hemos realizado permite constatar que, a lo largo de la década de 2010, muchos de los barrios localizados en los municipios centrales de las metrópolis de Barcelona y Madrid han conocido transformaciones sociodemográficas propias de los procesos de gentrificación. En general, son mayoría los barrios que han experimentado un rejuvenecimiento de su estructura demográfica, un aumento de la población nacida en países con un índice de desarrollo humano alto, un incremento de los hogares unifamiliares de adultos, un reforzamiento de la selectividad residencial, una mayor rotación poblacional y una intensificación de los procesos de sustitución poblacional a favor de los grupos más educados. Estos patrones generales nos hablarían de una década en la que la gentrificación habría penetrado como nunca antes en la geografía de ambas ciudades, una dinámica contrastable observando la amplia cobertura científica que el fenómeno ha recibido durante los últimos años (Ardura, Lorente y Sorando, 2021; Sánchez-Aguilera y González-Pérez, 2021; Solana-Solana et al., 2020; Sorando y Ardura, 2021).

No obstante, la intensidad con la que esas dinámicas se han manifestado ha sido espacialmente heterogénea. El índice que hemos propuesto nos ha permitido identificar qué barrios han experimentado con mayor intensidad cambios propios de los espacios gentrificados entre 2011 y 2019. En general, han sido los barrios céntricos de ambas ciudades, aunque no solo los cascos históricos, los que han vivido mayores cambios en ese sentido. En algunos casos se han reforzado procesos previos, mientras que en otros se trata de dinámicas incipientes. Más allá de esa zona central, el índice calculado permite observar los ejes que han tomado los procesos de gentrificación durante este periodo, y vislumbrar hacia qué espacios está avanzando. En Barcelona ha sido clara la expansión hacia los ejes de Poble Sec, Sants-Hostafrancs, Poblenou y Camp de l'Arpa del Clot, mientras que en Madrid los ejes del norte (Chamberí) y del noreste (Salamanca) son los ámbitos donde los procesos afines a la gentrificación están más consolidados y en el del sur donde aparecen los espacios más emergentes (Palos de Moguer y Chopera, por ejemplo). En esta dirección, es interesante observar las primeras señales de ruptura de la tradicional frontera socioeconómica de la M-30 y del Manzanares, plasmadas en los valores registrados en barrios como Puerta del Ángel y Comillas, una dinámica de la que se hacen eco otros autores (Sorando y Ardura, 2021).

En los márgenes territoriales de ambos municipios se encuentran los barrios que apenas han registrado cambios en las dimensiones contempladas en este estudio. Estos barrios corresponden a ámbitos de ingresos predominantemente bajos en los que se están experimentando otro tipo de dinámicas, asociadas a menudo con la llegada y concentración de población con más factores de vulnerabilidad (Porcel et al., 
2018; Hochstenbach y Musterd, 2021). Muchos de los barrios con un índice de gentrificación más bajo pertenecen a Madrid. En este sentido, no podemos dejar de mencionar los posibles efectos de la diferente dimensión de Barcelona y Madrid. Aunque los barrios de ambas ciudades son de tamaño muy similar, lo que los hace altamente comparables, la mayor superficie de Madrid, con muchos barrios alejados de las dinámicas sociodemográficas propias de los centros urbanos, explicaría que la gran mayoría de barrios con índices bajos se encuentren en la capital madrileña.

Por último, los tests estadísticos utilizados avalan la fortaleza de la aplicación de nuestro modelo teórico, pero también revelan que existen dos dimensiones que funcionan de forma específica en cada ciudad. Por un lado, la vinculación de los procesos de gentrificación con el aumento de población nacida en países de ingresos altos tiene una especial validez en el caso de Barcelona, mientras que en Madrid esta relación es mucho más diluida. La comparación entre los dos ámbitos evidencia el mayor peso de la gentrificación transnacional en Barcelona, que se ha manifestado con intensidad a lo largo de la década (Cocola-Gant y López-Gay, 2020). En cambio, la asociación entre el aumento de los hogares unipersonales de adultos con los espacios gentrificados es más fuerte en Madrid que en Barcelona, una situación que podría estar explicada por el freno que el aumento del precio de la vivienda ha representado para la expansión de este tipo de hogares en la capital catalana y que ha favorecido la rápida expansión de otras formas de convivencia, como los pisos compartidos.

\section{CONCLUSIÓN}

Valoramos de forma positiva el ejercicio que hemos realizado, ya que consideramos que el índice propuesto es robusto, posee una notable potencialidad como herramienta para la toma de decisiones y tiene un largo recorrido para el diagnóstico de los procesos de transformación urbana y de la composición sociodemográfica. Por un lado, la versatilidad del índice le permitiría integrar fácilmente otras dimensiones también asociadas a la gentrificación y que van más allá de los cambios sociodemográficos. Así, podrían incluirse indicadores que contemplen los cambios en la actividad comercial, en el mercado de la vivienda, en el paisaje urbano o en la actividad turística, por ejemplo. Por el otro, el índice podría ser una gran herramienta de monitoreo, casi a tiempo real, de los procesos de gentrificación, un aspecto fundamental para la toma de decisiones, ya que localiza los espacios en los que se están registrando los cambios más intensos. Asimismo, a medida que avance el tiempo y la serie de datos se alimente de más años de observación, se podrá comparar la intensidad de los procesos en diferentes momentos y comprender la forma en la que interaccionan en el tiempo y en el espacio cada una de las dimensiones del índice de gentrificación.

Este rastreo anual de los cambios que se han producido a escala geográfica detallada también tiene un fuerte potencial para descifrar el impacto que ha tenido la crisis de la COVID-19 en la transformación sociodemográfica de los barrios de nuestras ciudades. ¿Se habrá ralentizado, o incluso contraído, la expansión de los procesos de gentrificación debido a un mercado de la vivienda algo menos selectivo en estos espacios? O, en cambio, ¿se habrán fortalecido los procesos de desplazamiento como consecuencia del empeoramiento de las condiciones socioeconómicas de los estratos más bajos, que ya estaban en situación de alta vulnerabilidad antes del estallido de la pandemia? Será importante monitorizar las dinámicas resultantes, así como desarrollar acciones que mitiguen el impacto y garanticen una mayor justicia urbana y social, aún con más motivo tras la irrupción de la COVID-19.

\section{RECONOCIMIENTOS:}

Agradecemos al Departament d'Estadística de l'Ajuntament de Barcelona y al Servicio de Estadística Municipal del Ayuntamiento de Madrid el trabajo realizado para suministrarnos los datos utilizados en este artículo.

Esta investigación ha estado financiada por: Programa Talent, Universitat Autònoma de Barcelona; Ministerio de Ciencia e Innovación (GLOBFAM / RTI2018096730-B-I00); CERCA Programme / Generalitat de Catalunya.

\section{REFERENCIAS BIBLIOGRÁFICAS}

Anguelovski, I., Connolly, J. J., Masip, L., y Pearsall, H. (2018). Assessing green gentrification in historically disenfranchised neighborhoods: a longitudinal and spatialanalysis ofBarcelona.Urban Geography,39(3), 458-491. doi: 10.1080/02723638.2017.1349987

Antón-Alonso, F., Porcel, S. y Cruz, I. (2018). Factors contextuals associats als processos de gentrificació de l'àrea metropolitana de Barcelona. Papers: Regió Metropolitana de Barcelona, 60, 64-79. Recuperado de https://raco.cat/index.php/PapersIERMB/article/view/339241 
Ardura, A., Lorente, I., y Sorando, D. (2021). Vivir en la incertidumbre: burbuja de alquiler y olas de gentrificación entre crisis en Madrid. Revista INVI, 36(101). doi: 10.4067/S0718-83582021000100056

Atkinson, R. (2000). Measuring Gentrification and Displacement in Greater London. Urban Studies, 37(1), 149-165. doi: 10.1080/0042098002339

Atkinson, R., y Wulff, M. G. (2009). Gentrification and displacement: a review of approaches and findings in the literature. AHURI Positioning Paper, 115, 1-29.

Atkinson, R., Wulff, M., Reynolds, M. y Spinney, A. (2011). Gentrification and displacement: the household impacts of neighbourhood change. AHURI Final Report, 160, 1-89. Recuperado de https://apo.org.au/node/15334

Bailey, N. y Minton. J. (2018). The suburbanisation of poverty in British cities, 2004-16: extent, processes and nature. Urban Geography, 39(6), 892-915. doi: 10.1080/02723638.2017.1405689

Bayona, J. y López-Gay, A. (2011). Concentración, segregación y movilidad residencial de los extranjeros en Barcelona. Documents d'Anàlisi Geogràfica, 57(3), 381-412. doi: 10.5565/rev/dag.234

Benach, N. y Albet, A. (2018). La gentrificación como una estrategia global. Papers: Regió Metropolitana de Barcelona: Territori, estratègies, planejament, (60), 0017-23. Recuperado de https://raco. cat/index.php/PapersIERMB/article/view/339237

Bianco, F., Chapple, K., Kleiman, N., Sobolevsky, S., Chermesh, D., Xi, H., Rodríguez, G. y Hambardzumyan, R. (2018). Map of Gentrification and Displacement for The Greater New York. Recuperado de http://www.udpny.org/static/media/ report.8f3f1564.pdf

Bridge, G. (2006). It's not just a question of taste: gentrification, the neighbourhood, and cultural capital. Environment and Planning A, 38(10), 19651978. doi: 10.1068/a3853

Buzar, S., Ogden, P. E. y Hall, R. (2005). Households matter: the quiet demography of urban transformation. Progress in Human Geography, 29(4), 413-436. doi: 10.1191/0309132505ph558oa

Byrne, M. (2020). Generation rent and the financialization of housing: A comparative exploration of the growth of the private rental sector in Ireland, the UK and Spain. Housing Studies, 35(4), 743765. doi: 10.1080/02673037.2019.1632813
Cocola-Gant, A. (2018). Struggling with the leisure class: Tourism, gentrification and displacement (Tesis doctoral). Cardiff University, Cardiff. doi: 10.4337/9781785361746.00028

Cocola-Gant, A., y López-Gay, A. (2020). Transnational gentrification, tourism and the formation of 'foreign only'enclaves in Barcelona. Urban Studies, 57(15), 3025-3043. doi: 10.1177/0042098020916111

Díaz Parra, I. (2009). Procesos de gentrificación en Sevilla en la coyuntura reciente. Análisis comparado de tres sectores históricos: San Luis-Alameda, Triana y San Bernardo (2000-2006). Scripta Nova: revista electrónica de geografía y ciencias sociales, XII(304). Recuperado de https://revistes.ub.edu/ index.php/ScriptaNova/article/view/1610

Díaz Parra, I., y Apaolaza, R. (2020). Una propuesta metodológica para identificar gentrificación a partir de los censos de población. Estudios demográficos y urbanos, 35(3), 629-661. doi: 10.24201/ edu.v35i3.1883

Ding, L., Hwang, J. y Divringi, E. (2016). Gentrification and residential mobility in Philadelphia. Regional Science and Urban Economics, 61, 38-51. doi: 10.1016/j.regsciurbeco.2016.09.004

Domínguez-Mujica, J., Parreño-Castellano, J. M., y Moreno-Medina, C. (2020). Vacation rentals, tourism, and international migration: Gentrification in Las Palmas de Gran Canaria (Spain) from a diachronic perspective. En C. Ribeiro et al. (Eds.) Handbook of research on the Impacts, challenges, and policy responses to overtourism (pp. 237260). IGI Global.

Domínguez-Mujica, J., González-Pérez, J. M., ParreñoCastellano, J. M., y Sánchez-Aguilera, D. (2021). Gentrification on the Move. New Dynamics in Spanish Mature Urban-Tourist Neighborhoods. Urban Science, 5(1), 33. doi: 10.3390/urbansci5010033

Donat, Carles (2018). La gentrificació i el problema de I'habitatge a Barcelona. Papers: Regió Metropolitana de Barcelona, 60, 114-129. Recuperado de https://raco.cat/index.php/PapersIERMB/article/ view/339244

Duque-Calvache, R. (2010). La difusión del concepto gentrification en España: reflexión teórica y debate terminológico. Biblio $3 w$. Revista bibliografica de Geografia y Ciencias Sociales, XV(875), 1-23. Recuperado de http://www.ub.edu/geocrit/b3w875.htm 
Easton, S., Lees, L., Hubbard, P., y Tate, N. (2020). Measuring and mapping displacement: The problem of quantification in the battle against gentrification. Urban Studies, 57(2), 286-306. doi: 10.1177/0042098019851953

Freeman, L. (2005). Displacement or succession? Residential mobility in gentrifying neighborhoods. Urban Affairs Review, 40(4), 463-491. doi: 10.1177/1078087404273341

Garcia-López, M. À., Jofre-Monseny, J., MartínezMazza, R., y Segú, M. (2020). Do short-term rental platforms affect housing markets? Evidence from Airbnb in Barcelona. Journal of Urban Economics, 119, 103278. doi: 10.1016/j.jue.2020.103278

Glass, R. (1964). Introduction: aspects of change. In London: Aspects of Change. Centre for Urban Studies, Londres, Inglaterra: MacKibbon and Kee.

Gomà, R. (2018). La metròpoli entre la gentrificació i el dret a la ciutat. Papers: Regió Metropolitana de Barcelona: Territori, estratègies, planejament, 60, 10-14. Recuperado de https://raco.cat/index. php/PapersIERMB/article/view/339235

Hall, R., Ogden, P. E. y Hill, C. (1997). The pattern and structure of one-person households in England and Wales and France. International Journal of Population Geography, 3(2), 161-181. doi: 10.1002/(SICI)1099-1220(199706)3:2<161::AIDIJPG64>3.0.CO;2-2

Hamnett, C. (2000). Gentrification, postindustrialism, and industrial and occupational restructuring in global cities. En G. Bridge y S. Watson (Ed.), A Companion to the City. Oxford, UK; Victoria, Australia; Berlín, Alemania: Blackwell, pp. 331-341.

Herrera, L. M. G., Smith, N., y Vera, M. Á. M. (2007). Gentrification, displacement, and tourism in Santa Cruz de Tenerife. Urban Geography, 28(3), 276298. doi: 10.2747/0272-3638.28.3.276

Hochstenbach, C., y Musterd, S. (2021) A regional geography of gentrification, displacement and the suburbanization of poverty: towards an extended research agenda. Area. doi: 10.1111/area.12708

I-team. (2016). The Los Angeles Indices of Neighborhood Change. Recuperado de http://lahub.maps. arcgis.com/apps/MapJournal/index.html?appid= e3f1806c03fc4d0cbc7145aad8e523d9

Janoschka, M. (2018). Gentrificación en España reloaded. Papers: Regió Metropolitana de Barcelona: Territori, estratègies, planejament, 60, 24-33. Re- cuperado de https://raco.cat/index.php/PapersIERMB/article/view/339238

Janoschka, M., Sequera, J., y Salinas, L. (2014). Gentrification in Spain and Latinamerica-a Critical Dialogue. International journal of urban and regional research, 38(4), 1234-1265. doi: 10.1111/14682427.12030

Jolliffe, I. T. y Cadima, J. (2016). Principal component analysis: a review and recent developments. Philosophical Transactions of the Royal Society A, 374(2065), 20150202. doi: 10.1098/rsta.2015.0202

Kovács, Z., Wiessner, R., y Zischner, R. (2013). Urban renewal in the inner city of Budapest: Gentrification from a post-socialist perspective. Urban Studies, 50(1), 22-38. doi: 10.1177/0042098012453856

Lees, L., Bang Shin, H. y López-Morales, E. (2016). Planetary gentrification. Bristol, Inglaterra: Policy Press.

Ley, D. (1986). Alternative explanations for inner-city gentrification: a Canadian assessment. Annals of the association of american geographers, 76(4), 521535. doi: 10.1111/j.1467-8306.1986.tb00134.x

López-Gay, A. (2018). Cambio en la composición social y gentrificación en Barcelona: una mirada a través de los flujos migratorios y residenciales. Papers: Regió Metropolitana de Barcelona, 60, 80-93. Recuperado de https://raco.cat/index.php/PapersIERMB/article/view/339242

López-Gay, A., Andújar-Llosa, A., y Salvati, L. (2020). Residential Mobility, Gentrification and Neighborhood Change in Spanish Cities: A Post-Crisis Perspective. Spatial Demography, 8, 351-378. doi: 10.1007/s40980-020-00069-0

López-Gay, A., Cocola-Gant, A., y Russo, A. P. (2021). Urban tourism and population change: Gentrification in the age of mobilities. Population, Space and Place, 27(1), e2380. doi: 10.1002/psp.2380

Martin, I. W. y Beck, K. (2018). Gentrification, property tax limitation, and displacement. Urban Affairs Review, 54(1), 33-73. doi: 10.1177/1078087416666959

Martínez García, S. (2013). Estructura social y desigualdad en España. Madrid: Catarata.

Martínez Rigol, S. (2000). El retorn al centre de la ciutat. La reestructuració del Raval entre la renovació i la gentrificació (Tesis doctoral). Universitat de Barcelona, Barcelona. Recuperado de https:// www.tdx.cat/handle/10803/31847 
Módenes, J. A. (2019). L'insostenible augment de la inseguretat residencial a Espanya. Perspectives Demogràfiques, 13, 1-4. doi: 10.46710/ced.pd.esp.13

Módenes, J. A., y López-Colás, J. (2014). Cambio demográfico reciente y vivienda en España: ¿hacia un nuevo sistema residencial?. Revista Española de Investigaciones Sociológicas (REIS), 148(1), 103-133. doi: $10.5477 /$ cis/reis.148.103

Moos, M., Revington, N., Wilkin, T. y Andrey, J. (2019). The knowledge economy city: Gentrification, studentification and youthification, and their connections to universities. Urban Studies, 56(6), 1075-1092. doi: 10.1177/0042098017745235

Nel·lo, O. (2018). Segregació residencial, gentrificació urbana i dret a la ciutat: una lectura des de Barcelona. Papers: Regió Metropolitana de Barcelona, 60, 48-61. Recuperado de https://raco.cat/index. php/PapersIERMB/article/view/339240

Newman, K. y Wyly, E. K. (2006). The right to stay put, revisited: Gentrification and resistance to displacement in New York City. Urban studies, 43(1), 23-57. doi: 10.1080/00420980500388710

Ogden, P. E. y Schnoebelen, F. (2005). The rise of the small household: demographic change and household structure in Paris. Population, space and place, 11(4), 251-268. doi: 10.1002/psp.370

Peña, D. (2002). Análisis de datos multivariantes. Madrid, España: McGraw-Hill Interamericana de España S.L.

Porcel, S. (2016). Dinámicas de estructuración socioresidencial en la Barcelona metropolitana postindustrial ¿hacia una ciudad dual o cuarteada? (Tesis doctoral). Universitat Autònoma de Barcelona, Barcelona. Recuperado de https://tdx.cat/ handle/10803/399521

Porcel, S., Navarro-Varas, L., Antón-Alonso, F. y Cruz, I. (2018). La suburbanització de la pobresa com a efecte metropolità de la gentrificació: el cas de Barcelona. Papers: Regió Metropolitana de BarceIona, 60, 95-113. Recuperado de https://raco.cat/ index.php/PapersIERMB/article/view/339243

Rérat, P. y Lees, L. (2011). Spatial capital, gentrification and mobility: evidence from Swiss core cities. Transactions of the Institute of British Geographers, 36(1), 126-142. doi: 10.1111/j.14755661.2010.00404.x

Riera, J. (2018). L'índex de gentrificació de Barcelona. Barcelona, Espanya: Edicions Els Llums.
Rousseau, M. (2009). Re-imaging the city centre for the middle classes: Regeneration, gentrification and symbolic policies in 'loser cities'. International Journal of Urban and Regional Research, 33(3), 770-788. doi: 10.1111/j.1468-2427.2009.00889.x

Rubiales Pérez, M. (2016). Territorio y crisis. Impacto territorial de la crisis económica en las regiones metropolitanas de Madrid y Barcelona. Scripta Nova. Revista Electrónica de Geografía y Ciencias Sociales, XX, 549. doi: 10.1344/sn2016.20.17208

Rubiales, M. (2017). Patrones socioterritoriales de las clases altas en las regiones metropolitanas de Barcelona y Madrid (2001 - 2015) (Tesis doctoral). Universitat de Barcelona, Barcelona. Recuperado de https://www.tesisenred.net/handle/10803/462770

Rubiales, M., Bayona, J. y Pujadas, I. (2012). Patrones espaciales de la segregación residencial en la Región Metropolitana de Barcelona: Pautas de segregación voluntaria de los grupos altos. Scripta Nova. Revista Electrónica de Geografía y Ciencias Sociales, XVI, 423. Recuperado de http://www. ub.edu/geocrit/sn/sn-423.htm

Sales-Favà, J. (2019). Especialització turística, gentrificació i dinàmiques residencials en un entorn urbà madur: el cas de Barcelona (Tesis doctoral). Universitat Autònoma de Barcelona, Barcelona. Recuperado de https://www.tesisenred.net/handle/10803/667898

Sánchez-Aguilera, D., y González-Pérez, J. M. (2021). Geographies of Gentrification in Barcelona. Tourism as a Driver of Social Change. En Dominguez-Mujica J. et al. (Eds.) International Residential Mobilities (pp. 243-268). Springer, Cham. doi: 10.1007/9783-030-77466-0_13

Sarasa, S., Navarro, L. y Porcel, S. (2017). Escenari post-crisi i estructura social metropolitana: vulnerabilitats $i$ cobertura de necessitats des d'una mirada de clase. Bellaterra: IERMB. Recuperado de https://iermb.uab.cat/ca/estudi/monografic-enquesta-de-condicions-de-vida-ecv-2016-escenari-post-crisi-i-empobriment-economic-de-les-classes-mitjanes-metropolitanes/

Sassen, S. (1991). The global city. Nueva York, Estados Unidos: Princeton University Press.

Sequera, J. (2013). Las politicas de la gentrificacion en la ciudad neoliberal. Nuevas clases medias, produccion cultural y gestión del espacio público. el caso de Lavapies en el centro historico de Madrid (Tesis doctoral). Universidad Complutense de Ma- 
drid, Madrid. Recuperado de https://eprints.ucm. es/id/eprint/23816/

Solana-Solana, A. M., Ortiz-Guitart, A., y López-Gay, A. (2020). "Me están echando de mi casa». Repercusiones personales y sociales de la inseguridad residencial en Barcelona. Papers. Revista de Sociologia, 1(1), 1-24. doi: 10.5565/rev/papers.2842

Sorando, D. y Ardura, A. (2018). Procesos y dinámicas de gentrificación en las ciudades españolas. Papers: Regió Metropolitana de Barcelona, 60, 34-47. Recuperado de https://raco.cat/index.php/ PapersIERMB/article/view/339239

Sorando, D., y Ardura, A. (2021) Desplazamiento: la gentrificación como proceso de expulsión en Madrid. Documentación Social, 1(1), 1. Recuperado de https://documentacionsocial.es/7/a-fondo/desplazamiento-gentrificacion-proceso-expulsion-madrid/

Sorando, D. y Leal, J. (2019). Distantes y desiguales: el declive de la mezcla social en Barcelona y Madrid. Revista Española de Investigaciones Sociológicas, 167, 125-148. doi: 10.5477/cis/reis.167.125

Trilla, C., Donat, C., Vergés, A., López, J., Sánchez, A. y Arcarons, A. (2018) L'habitatge a la metrò- poli de Barcelona, 2017. Observatori Metropolità de l'Habitatge de Barcelona. Recuperado de https://iermb.uab.cat/ca/estudi/lhabitatge-a-lametropoli-de-barcelona-informe-anual-2017/

Verma, P., Rinzler, D., Zuk, M., DaSilva, M. y Kaplan E. (2018). Rising Housing Costs and Re-Segregation in San Francisco. Recuperado de https://www.urbandisplacement.org/sites/default/files/images/ sf_final.pdf

Vila Márquez, F. (2016). La (in) esperada gentrificación cultural. El caso Barcelona. Periférica, 17, 285297. doi: 10.25267/Periferica.2016.i17.21

Vives-Miró, S. y Rullán, O. (2017). Desposesión de vivienda por turistización?: Revalorización y desplazamientos en el Centro Histórico de Palma (Mallorca). Revista de Geografía Norte Grande, (67), 53-71. doi: 10.4067/S0718-34022017000200004

Yrigoy, I. (2017). Airbnb en Menorca:¿ Una nueva forma de gentrificación turística? Localización de la vivienda turística, agentes e impactos sobre el alquiler residencial. Scripta Nova. Revista Electrónica de Geografía y Ciencias Sociales, 21. doi: 10.1344/sn2017.21.18573 
ANEXO 1

DIVISIÓN ADMINISTRATIVA DE BARCELONA Y MADRID, 2011

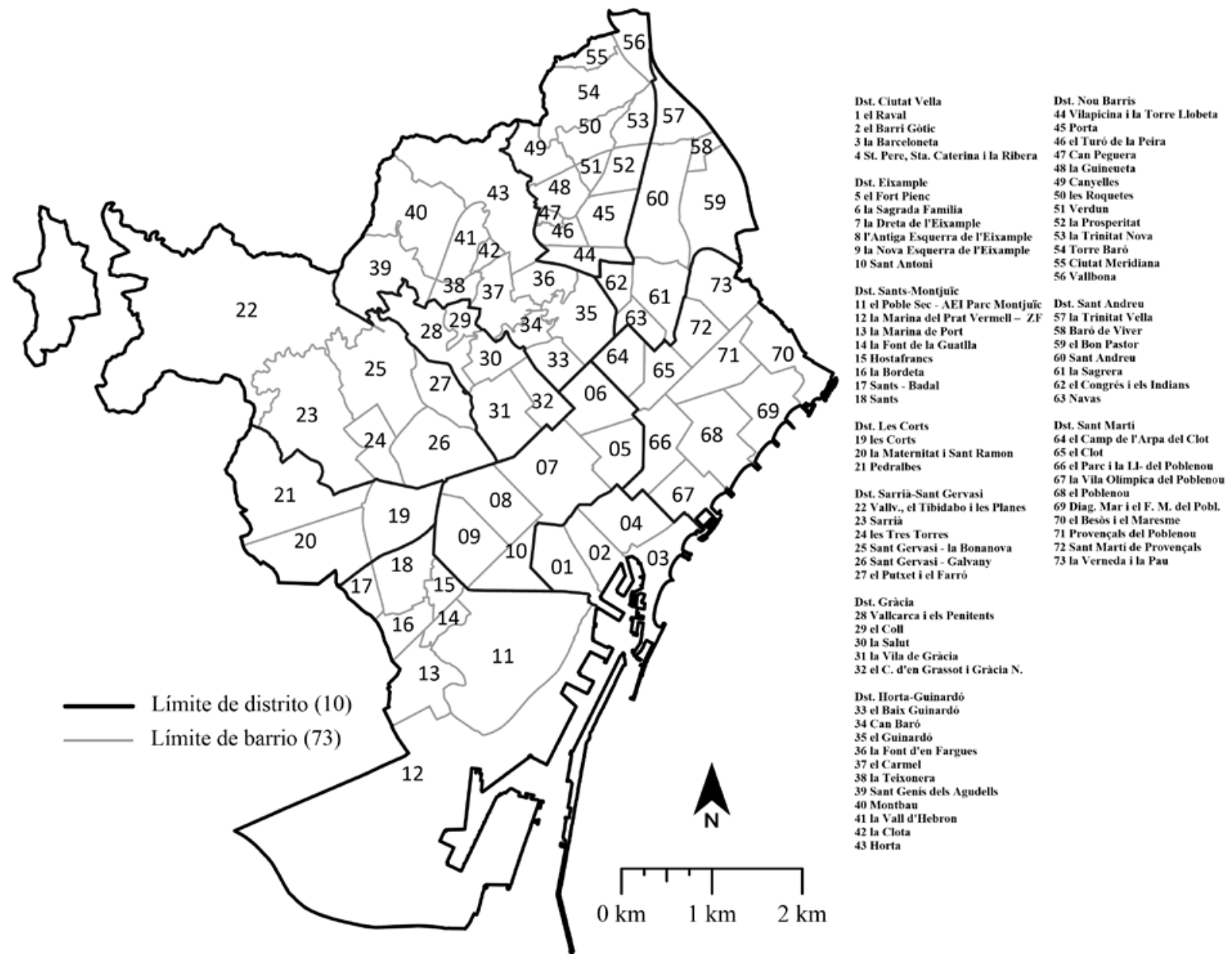




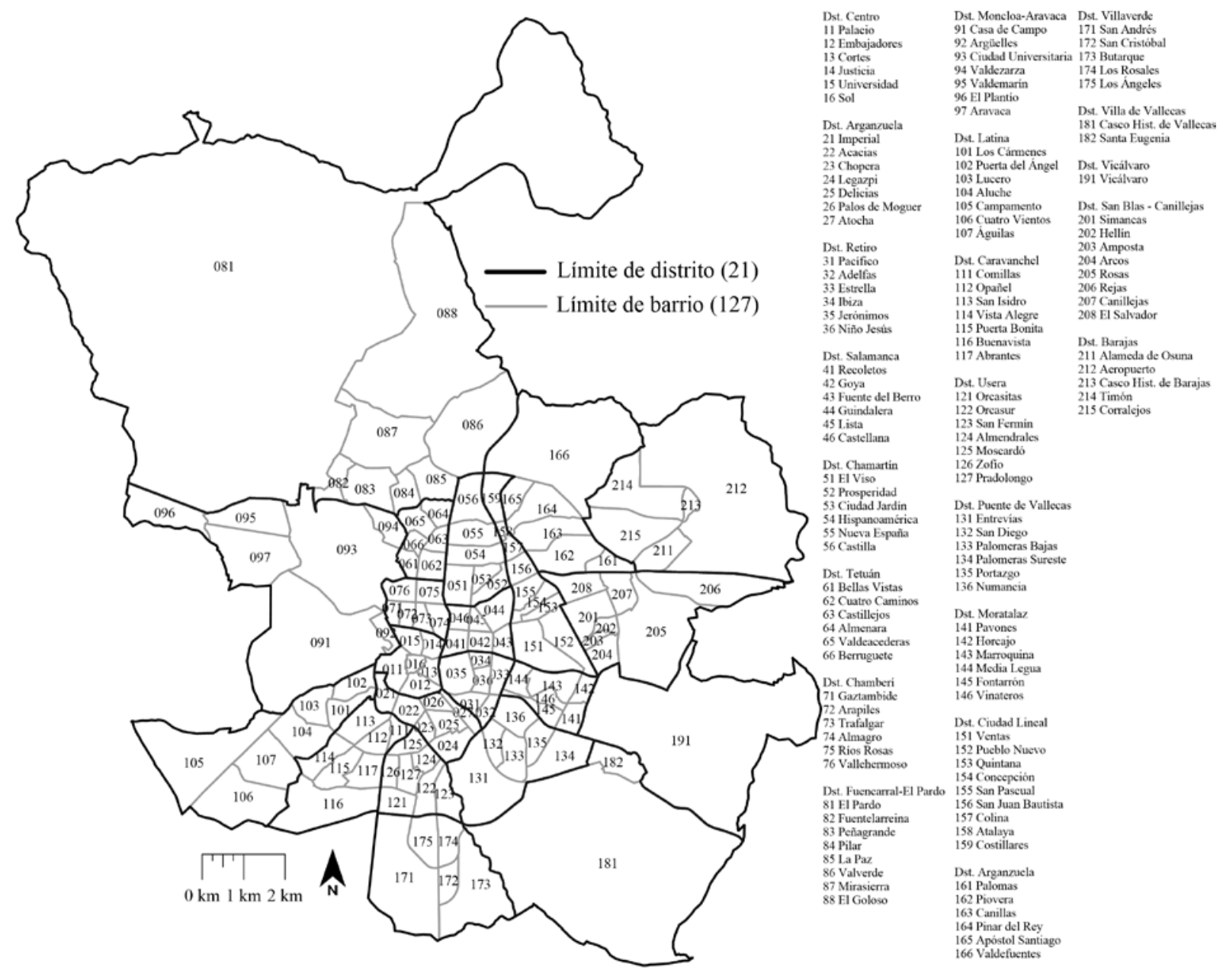


ANEXO 2

CLUSTERING JERÁRQUICO SOBRE EL PRIMER COMPONENTE DEL ANÁLISIS DE COMPONENTES PRINCIPALES (3 CONGLOMERADOS)

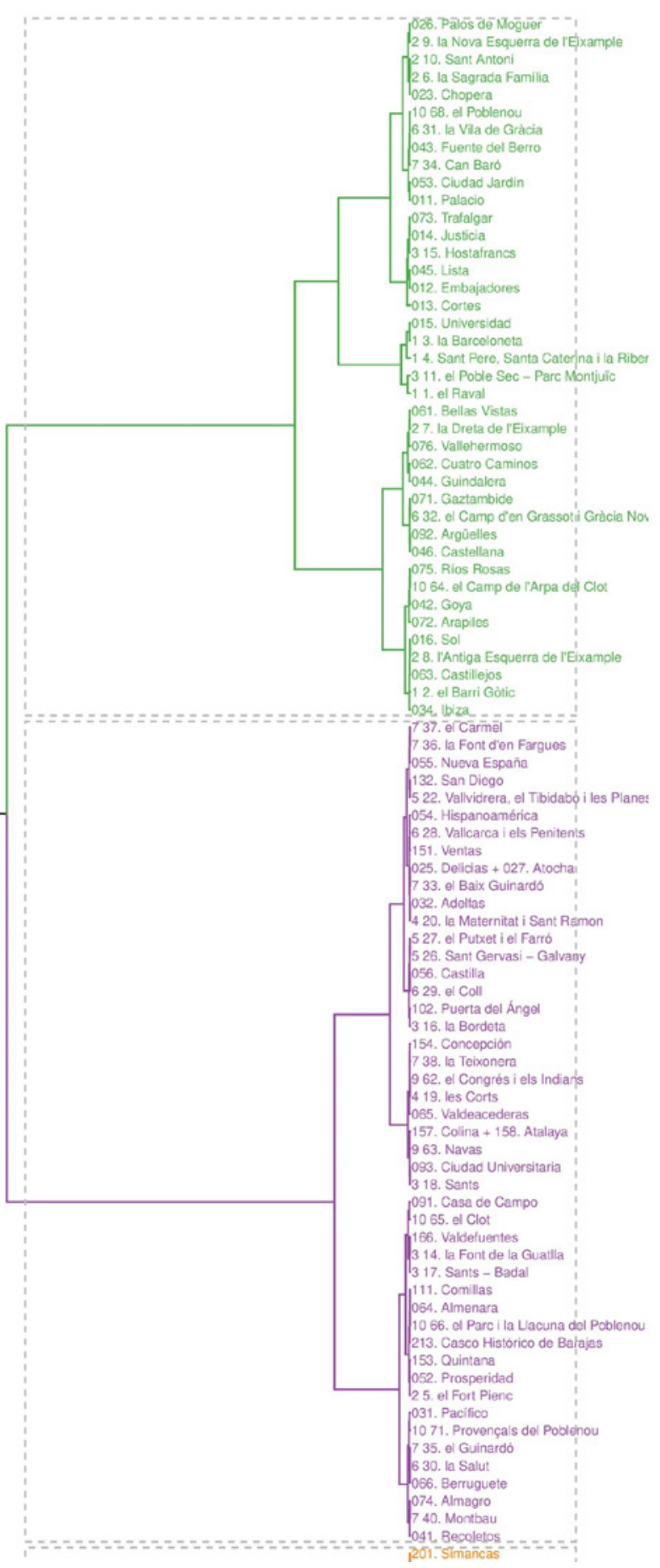




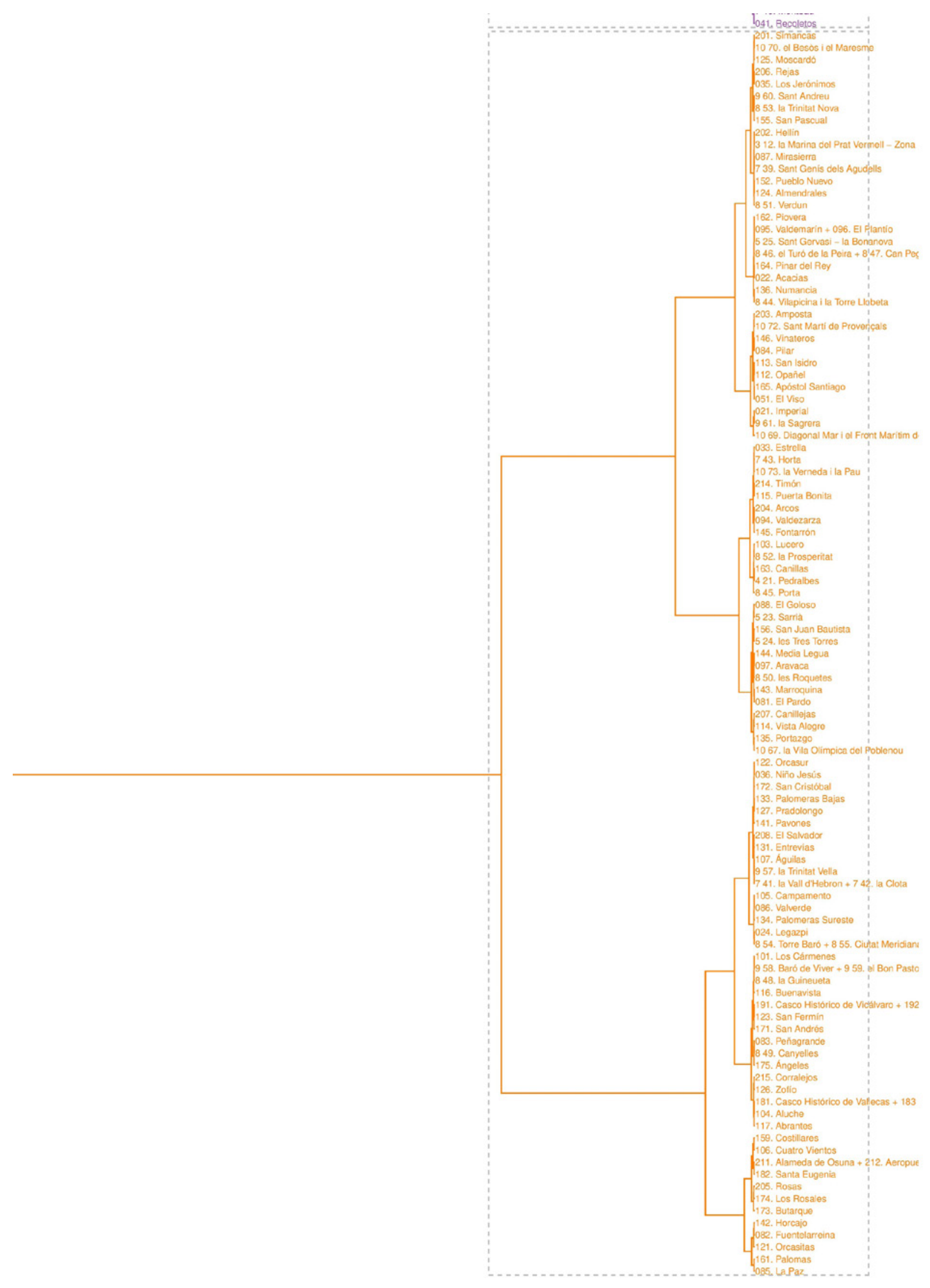

